\title{
A DETERMINAÇĀO DE SELÊNIO POR FLUORIMETRIA
}

\section{ARQUIMEDES LAVORENTI}

Orientador: Prof. HENRIQUE BERGAMIN FILHO

Dissertação apresentada à Escola Superior de Agricultura “Luiz de Queiroz", da Universidade de São Paulo, para obtenção do título de Mestre em Energia Nuclear na Agricultura.

P IR A C I C A B A

Estado de São Paulo - Brasil

Novembro - 1981 
Aos meus pais e imãos

OFEREC O

A minha noiva, Walkiria Bertinato Cardoso, que sempre soube me compreen der, estimular e ajudar nas horas dificeis

DEDICO 
AGRADECIMENTOS

\section{Agradeço:}

- ao Professor da ESALQ e Diretor do INPA, Dr. Henrique Bergamin Filho, pela sua orientação e apoio.

- ao Pesquisador Científico, Chefe da Seção de Radioquímica e Química Analítica do CENA, Francisco José Krug, pela amizade e inestimável ajuda.

- ao Pesquisador Científico do CENA, Dr. Elias Ayres Guidetti Zagatto, pela amizade, sugestões e revisão do texto.

- ao Professor da ESALQ-CENA, Dr. Antonio Otávio Jacintho, pela amizade e sugestões apresentadas.

- ao Professor da ESALQ-CENA, Dr. Virgilio F. Nascimento Filho pela amizade e auxilio no preparo do material radioativo.

- ao Pesquisador Científico do IAC, Dr. Ondino Cleante Bataglia pela amizade e sugestões apresentadas.

- aos Técnicos de Laboratório do CENA, Neusa Maria Mendes Tonin, Eunice Raquel zen, Iolanda Aparecida Rufini e Oscar Bahia Filho, pelo auxílio constante, amizade e espírito de cooperação.

- às Secretárias, Juraci de Castro L. Lourencetti (IAC), Neusa Maria C. Pereira (CENA) e Edna Cortez Ribeiro (Elanco Quimica Ltda.), pela datilografia dos originais deste trabalho e pela amizade.

- ao Centro de Energia Nuclear na Agricultura (CENA), pelas fa cilidades oferecidas. 
- à Comissão Nacional de Energia Nuclear (CNEN), pela concessão da bolsa de mestrado.

- à Agência Intermacional de Energia Atômica (IAEA), pela compra do selênio radioativo.

- à'Seção de Química Analitica do IAC, na pessoa do Pesquisador Científico Chefe, Dr. Ruter Hiroce, pelas facilidades ofereci das na realização de parte deste trabalho.

- ao Centro de Pesquisas Agropecuárias da Elanco Química Ltda., na pessoa do seu Diretor Dr. Jemy Clyde Walker, pela amizade e facilidades oferecidas.

- ao ex-Diretor e ao Gerente de Registro e Relações Cientificas da Elanco Química Ltda., Aldo Alves e Guilherme Luiz Guima rães, respectivamente, pela amizade e incentivo.

- ao colega Wagner Mello d'Ávila, pela amizade e ajuda em escre ver o "Summary".

- ao colega Benedito Herculano Davanzo, responsável pela gráfica do CENA, pela amizade e ajuda na confecção desțe trabalho.

- aos funcionários do CENA, pelo convivio, amizade e apoio a mim proporcionados.

- a todos que, de uma forma ou de outra, contribuíram para a realização deste trabalho. 
INDICE

Pågina

LISTA DE TABELAS. ............................ viii

LISTA DE FIGURAS..........................

RESUMO.................................... xii

SUMMARY................................... xiii

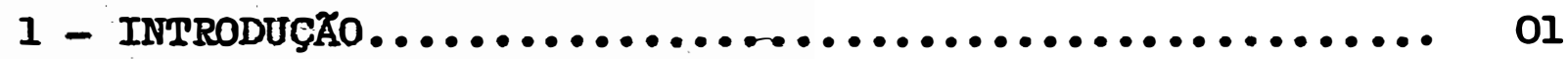

2 - IMPORTÂNCIA DO SELENIO NA AGROPECUARIA........... O3

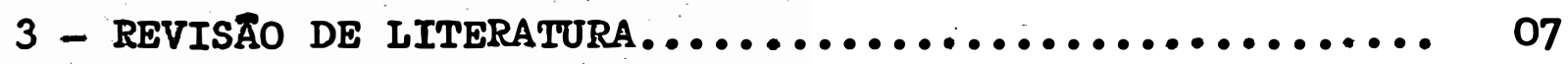

3.1. Métodos Analiticos..................... 07

3.1.1. Colorimétricos................... 07

3.1.2. Fluorimétricos ................... 09

3.1.3. Espectrométricos de absorção atômica..... 14

3.1.4. Outros métodos................... 16

3.2. Decomposição de Amostras.................. 18

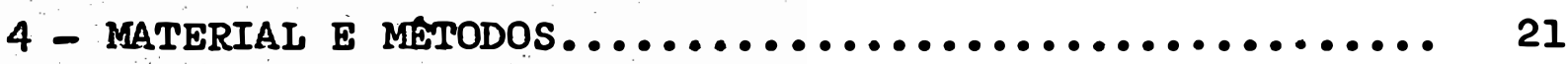

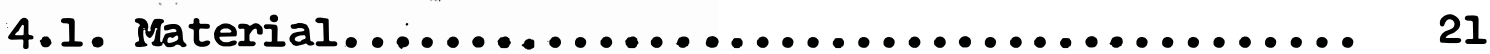

4.1.1. Instrumentos e acessórios............ 21

4.1.2. Vidrarias especiais................. 23

4.1.3. Reagentes e soluções................. 23

4.1.4. Amostras........................ 26

4.1.4.1. Material vegetal............ 26

4.1.4.2. Soro de sangue............... 26

4.2. Métodos................................ 26

4.2.1. Metodologia de detecção de ${ }^{75}$ se........ 26

4.2.1.1. Espectro de raios gama de ${ }^{75}$ se.. 27

4.2.1.2. Efeito da geometria das amostras na detecção de ${ }^{75}$ se............ 
4.2.2. Decomposição de amostras..............

4.2.2.1. Via úmida com ácidos nitrico e perclórico.................. 29

4.2.2.2. Via úmida com ácidos sulfúrico e perclórico...................

4.2.2.3. Via seca com frasco de combustão de schoniger................. 33

4.2.3. Metodologia de determinação........... 35 4.2.3.1. Concentração do 2,3-diaminonaftaleno (DAN) ...................

4.2.3.2. Efeito do tempo e temperatura na reação.................... 36

4.2.3.3. Influência do solvente orgânico. 4.2.3.4. Efeito da razão fase aquosa/fase orgânica................... 39

4.2.3.5. Cinética de extração......... 40

4.2.3.6. Número de extrações........... 40

4.2.3.7. Precisão e exatidão do método... 41

5 - RESULTADOS E DISCUSSAO...................... 43

5.1. Metodologia de deteç̧ão de ${ }^{75}$ se.............. 43

5.1.1. Espectro de raios gama de ${ }^{75}$ Se.......... 43

5.1.2. Efeito da geometria das amostras na detecção de ${ }^{75}$ Se......................... 46

5.2. Decomposição de amostras.................. 48

5.2.1. Via úmida com ácidos nítrico e perclórico. 48

5.2.2. Via úmida com ácidos sulfúrico e perclóri-

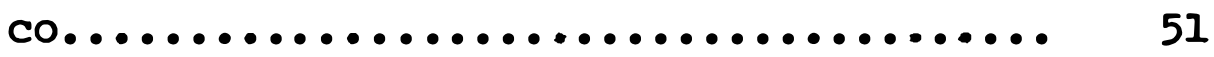

5.2.3. Via seca com frasco de combustão de Sch8_niger. 
vii

5.3. Metodologia de determinação................ 56 5.3.1. Concentração do 2,3-diaminonaftaleno(DAN) 56 5.3.2. Efeito do tempo e temperatura na reação.. 56 5.3.3. Influência do solvente orgânico........ 58 5.3.4. Efeito da razão fase aquosa/fase orgânica 61 5.3.5. Cinética de extração................. 64 5.3.6. Número de extrações.................. 64 5.3.7. Precisão e exatiaão do método........... 68 6 - CONCLUSర్ES............................... 73

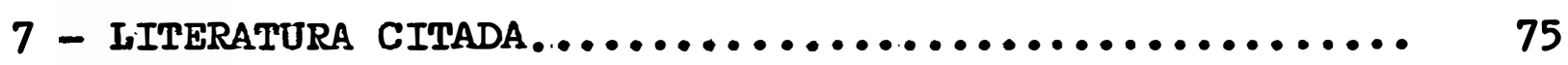




1 Teores médios de selênio ( $\mathrm{ppm}$ ) em diferentes matrizes................................. 06

2 Características físicas dos solventes orgânicos utilizados.............................. 38

3 Tratamentos referentes ao estudo da razão fase aquosa/fase orgânica......................... 39

4 Estudo de cinética de extração do complexo Se-DAN por diferentes autores...................... 40

5 Recuperação de selênio em material vegetal na digestão nitrico-perclónica................. 48

6 Recuperação de selênio em soro de sangue na digestão nîtrico-perclọ́rica.................. 51

7 Recuperação de ${ }^{75}$ Se em silagem de milho através do frasco de combustão de schuniger.............

8 Estudo de diferentes solventes orgânicos como extratores do complexo Se-DAN................ 60

9 Efeito do número de extrações do complexo Se-DAN com ciclohexano.......................... 66

10 Efeito do mnúmero de extrações do complexo Se-DAN com diferentes solventes....................

11 Resultados do teor de selênio na amostra referência de soro de sangue, pela curva padrão........... 68 
TABELA No Pågina

12 Precisão da deteminação e recuperação de selênio na referência de soro de sangue............... 
IISTA DE FIGURAS

FIGURA №

1

2

3

4 Recuperação de selênio em material vegetal na

5

5 Recuperação de selênio em soro de sangue em digestão nítrico-perclórica................. Efeito da geometria das amostras na detecção de ${ }^{75}$ se de $10 \mathrm{nCi} / \mathrm{ml}$. digestão nitrico-perclórica.

6 Recuperação de selênio em soro de sangue em digestão sulfo-perclorica..................

7 Recuperação de selênio em ração em digestão sulfo-perclórica.......................

8 Influência da concentração de DAN na extração de selênio.

9 Efeito do tempo e da temperatura na formação do complexo Se-DAN.

10 Efeito da razão fase aquosa/fase orgânica com fase aquosa constante ao redor de $21,5 \mathrm{ml}$ e fase orgânica variando de 2 a $6 \mathrm{ml} . . . . . . . . . .$. 
11 Efeito da razão fase aquosa/fase orgânica com fase aquosa constante ao redor de 21,5 ml e fase orgânica variando de 2 a $10 \mathrm{ml} . . . . .63$

12 Efeito do tempo de agitação das duas fases para transferência do complexo Se-DAN para a fase orgânica de ciclohexano.............. 65

13 Curva padrão de selênio em solução aquosa..... 69

14 Curva padrão do selênio pela técnica do padrão interno. 
A DETERMINAÇÃO DE SELENTO POR

FLUORINIETRIA'

Arquimedes Lavorenti

Orientador: Dr. Henrique Bergamin Fo

RESUMO

Foi desenvolvido um método fluorimétrico para a determinação de selênio em amostras vegetais e soro de sangiue. 0 método empregou inicialmente o radioisótopo ${ }^{75}$ se para atingir as condições analiticas de determinação.

Foram estudados três processos de digestão de amostras e alguns fatores relativos à metodologia. Com o proces so de digestão nitrico-perclórica, cerca de 40 amostras podem ser analisadas diariamente com relativa facilidade.

Foi adicionado HCl $(1+9)$ ao digerido e submetido ao banho-maria a 90C por 30 minutos. 0 procedimento analítico básico consistiu na reação do selênio com 2,3-diaminonaftaleno (DAN) $4 \times 10^{-3} \mathrm{M}$ a $\mathrm{PH} 2$ durante 60 minutos a $700 \mathrm{C}$ e extração do complexo Se-DAN com ciclohexano.

o método proposto apresentou um coeficiente de variação em torno de 9\%, uma recuperação média superior a 90\% e uma exatidão considerada excelente. 
SELENIUM DETERMINATION BY

ETITORTMFTRY

Arquimedes Iavorenti

Adviser: Dr. Henrique Bergamin Fo

\author{
SUMMARY
}

A fluorimetric method was developed to determine selenium both in vegetal samples and blood serum. The method consists of a radioisotope ${ }^{75}$ se initially in order to optimize the determination of analytical conditions.

Three samples digestion processes were studied and also some factors related to methodology. Thanks to the nitric-percloric digestion process, around 40 samples can be analysed daily in a relatively easy way.

$\mathrm{HCl}(1+9)$ was added to the digested material and submitted to water-bath at $900 \mathrm{C}$ during 30 minutes. The basic analytical process consisted of the selenium reaction with 2,3diaminonaphthalene (DAN) $4 \times 10^{-3} \mathrm{M}$ at $2 \mathrm{pH}$ during 60 minutes at $700 \mathrm{c}$ and extraction of Se-DAN complex with cyclohexane.

The proposed method showed a coefficient of variation of about $9 \%$, an average recovery superior to $90 \%$ and excellent accuracy. 


\section{1 - INTRODUÇÃo}

o selênio foi identificado como um elemento en 1817 por um químico sueco, Berzelius, em resíduos de produção de ácido sulfurico. Ele foi denominado da pàlavra grega selene, significando a lua, por causa de sua semelhança ao telúrio, um elemento que havia sido descoberto anteriormente e foi denominado da palavra latina tellus, significando a terra (ROSENFELD e BEATH, 1964). Faz parte da familia do enxofre, coluna 6A dos não metais, parecendo-se com o mesmo em seus compostos:

Apesar de ser um elemento muito utilizado na indústria (produção de retificadores, fotômetros, semi-condutores, etc.), seus compostos são extremamente tóxicos, asseme lhando-se aos do arsênico nas reações fisiológicas em animais. o selênio é um elemento que pode estar presente no solo e ser absorvido pelas plantas em quantidades suficientes capaz de ocasionar toxidez aos animais que se alimentam dessas plantas. Também é tóxico à maioria das plantas, com exceção de algumas espécies que são acumuladoras de selênio,como as leguminosas do gênero Astragalus, (TRELEASE, 1945).

Tem sido reconhecido desde 1957 como um elemento essencial à vida animal. Este reconhecimento se deve aos expe- 
rimentos realizados por SCHWARZ e FOLTZ (1957), que descobriram um componente vital no "Fator 3" (um composto orgânico contendo selênio como ingrediente ativo), altamente eficaz na proteção contra a necrose hepática dos ratos.

No Brasil, poucos são os estudos realizados com selênio en termos de nutrição animal. Tudo indica que o principal motivo seja a falta de conhecimento sobre a metodologia uti lizada para a sua determinação.

Foi pensando nisto que o objetivo do presente tra balho visou aprimorar o método de determinação de selênio por fluorimetria, principalmente em termos de sensibilidade, exatidão, precisão, velocidade analftica e custo operacional, de tal modo que o método fosse prático e de rotina em muitos laboratórios que disponham de um minimo de equipamentos e reagentes necessários.

Poder-se-ia ter escolnido um dos métodos já existentes na literatura e implantá-lo integralmente no Brasil, mas como será abordado mais adiante na revisão de literatura, estes métodos não aliam boas condições em ambas as fases do procedimento para análises de rotina: decomposição de amostras e deter minação de selênio propriamente dita. 
2 - IMPORTANCIA DO SELENIO NA AGROPECUARIA

A importância do selênio é devida principalmente ao fato de ser este elemento essencial à vida animal. As plantas podem absorvê-lo em diferentes quantidades, e se concentram principalmente nas sementes (TRELEASE, 1945).

Segundo GEERING et alii (1968), a solubilidade do selênio nos solos é uma função do pH. A solubilidade diminui quando a solução do solo está na faixa levemente ácida para neutra. Foi verificado também, que o selênio está presente principalmente na forma de selenito e é facilmente fixado pelos oxidos de ferro e matéria orgânica.

CARY e ALLAWAY (1969) mediram a absorção de selê nio adicionado à cultura de alfafa crescendo em quatro tipos de solo e dois níveis de $\mathrm{PH}$ (um em torno de 5,5 e outro 7,5). Constataram que as plantas absorveram mais selênio quando cres ciam em solos arenosos e em $\mathrm{pH}$ mais elevado.

Segundo GISSEL-NIELSEN (1971), as plantas utilizam apenas $1 \%$ do selênio contido nos fertilizantes, podendo aumentar a absorção quando se utiliza um fertilizante NPK pobre en enxofre. O mesmo autor (1975) salienta que a correção 
de deficiências de selênio no solo também pode ser feita com pulverizações foliares nas plantas jovens, onde se gastariam vinte vezes menos selênio do que aplicar o fertilizante no so10. Ainda poderia ser feito o pré-tratamento das sementes com selênio, antes da semeadura.

GISSEL-NIELSEN (1973) verificou que a absorção de selênio pelas plantas é dependente do seu estado de oxida ção e, a adição de enxofre ao solo diminui a absorção de selê_ nio principalmente como selenato. 0 selênio é translocado das raizes com maior rapidez como selenato do que como selenito.

Os mecanismos responsáveis pela fixação do selênio nos solos não são totalmente explicados devido à falta de informações a respeito das reações entre os componentes do so10 e o selênio (HAMDY e GISSEL-NIELSEN, 1977). O entendimento destas reações é de grande importância para elucidar os fatores que levam a não disponibilidade do selênio às plantas.

A ocorrência de selenosis nos animais em regime de pastoreio, depende da interação entre as quantidades e formas de selênio no solo e as espécies de plantas que estão presentes. Elevados niveis de selênio total no solo não resultam necessariamente em elevados niveis de selênio nas plantas, por que o selênio pode estar presente principalmente na forma não disponivel no solo.

Assim, LEVANDER (1967), estudando o selênio em diferentes aspectos, observou que o mesmo é um mineral raro que pode estar em pastagens naturais juntamente com outros ele mentos, ocasionando toxidez ou deficiência em animais que ve nham a se alimentar destas pastagens. Por volta de 1930 nos Estados unidos foi constatado que alimentos contendo selênio ocasionavam a "enfermidade de alcali" em animais domésticos. 
Os sintomas de toxicidade do selênio variam com o nivel, natureza e tempo de absorção, com a dieta e em pequena extensão, com a idade e espécie animal. Segundo MAYNARD e UNDERWOOD (1966), nos casos crônicos da doença, ocorre a perda dos pelos, das crinas e dos rabos nos cavalos, no pelo do rabo no gado bovino e despreendimento de pelos no gado porcino. Produz esfoliação dos cascos e se tormam inflamados e ainda pode haver queda dos cornos. 0 animal também se torna manco, devido ao desgaste das juntas dos ossos longos, 0 animal enfraque ce, diminui o consumo de alimentos, o corpo definha e pode morrer de fome. Estes sintomas externos se unem a marcantes altera ções internas que se revelam na autópsia, como atrofia do muscu 10 do coração, cirrose do fígado e anemia hipocrônica de severí dade progressiva. Nas enfermidades agudas o animal mostra ceguei ra, sofrimento abdominal, salivação excessiva, dentes ásperos e alguns graus de paralisia. A respiração é perturbada e a morte surge com a quebra da respiração. Os mais susceptíveis a essa toxidez são os animais jovens, cujo crescimento se retarda pela injestão de pequenas quantidades de selênio.

A distribuição do selênio no meio ambiente em diferentes matrizes pode ser observado na Tabela 1, extraida de BOWEN (1966). 
TABELA 1. Teores médios de selênio (PPm) em diferentes matrizes (extraido de BOWEN, 1966).

Rocha 1gnea.......... 0,05

Argila ou xisto. ......... 0,60

Arenito ........... 0,05

Rocha calcárea ........ 0,08

Carvão de pedra. . . . . . . . $\leq 7$

Agua do mar. ........... 0,00009

Agua de rios ........ 0,02

solos secos.......... 0,2

Plantas marinhas (algas pardas). . . 0,84

Plantas terrestres (angiospermas). - 0,2

Mamiferos. . . . . . . . 1,7

cérebro . . . . . . 2,10

Coração ........ 0,70

$\operatorname{Rim}$......... 2,10

Fígado. . . . . . . . 2,10

Musculos........ 2,50

Cabelo......... 0,3-1,3

Sangue. . . . . . . 0,27

Plasma. ......... 0,11

ossos .......... 0,06 
3 - REVISÃo DE LITERATURA

A presente revisão tem por finalidade destacar os métodos analiticos utilizados para determinação quantitativa do selênio e os métodos de decomposição de amostras.

3.1. Métodos Analiticos

\subsubsection{Colorimétricos}

Dentre os métodos colorimétricos utilizados: para determinação de selênio, o métodó baseado no 3,3'-diaminobenzidina (DAB) é o mais usado e sensivel. o selênio e determinado apర́s extração do complexo Se-DAB em solvente orgânico.

0 mecanismo da reação de selênio com DAB foi descrito por HOSṬE (1948) e, segundo este autor, a reação independe de um processo de oxi-redução. Basicamente uma molécula de DAB reage em meio aquoso com duas moléculas de ácido selenoso $\left(\mathrm{H}_{2} \mathrm{SeO}_{3}\right)$ e um precipitado amarelo difenildipiazselenol é formado imediatamente:

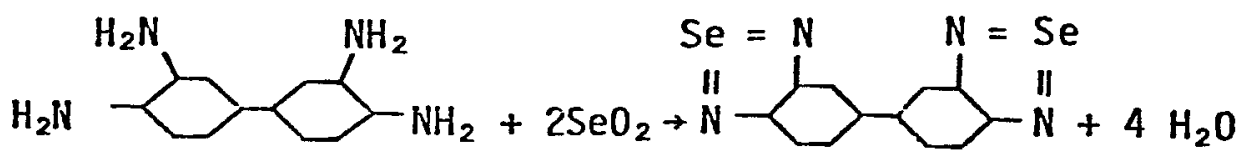


0 composto é insolável em água, $\mathrm{HNO}_{3} 6 \mathrm{~N}, \mathrm{HCl} 11 \mathrm{~N}$ ou $\mathrm{NH}_{3}, 6 \mathrm{~N}$ e levemente solkvel en álcool e ácido glacial em ebu lição (HOSTE; 1948).

O método descrito por HOSTE e GILLIS (1955), para determinar baixas concentrações de selênio com DAB, foi modifí cado por CHENG (1956) que empregou EDTA para "mascarar" o efei to de ions interferentes. Concluiu que apenas aquelas substâncias que oxidam o diaminobenzidina ou reduzem o selenito ele mentar interferem no método. o complexo Se-DAB se desenvolve entre $\mathrm{pH} 2$ e 3, extraído com tolueno a $\mathrm{pH} 7$ e a absorbância da solução medida a $420 \mathrm{~nm}$.

Segundo o método de DANZUKA e UENO (1958) de determinação de selênio em ácido sulfurico, pequenas quantidades de selênio (IV) podem ser determinadas em ácido sulfGrico ou amostras contendo sulfato. A interferência do ion sulfato é eliminada pela adição de um excesso de cloreto de amônio antes da reação do selênio com $D A B$.

GUTENMANN e LISK (1961) adaptaram o método de CHENG (1956) para determinação de selênio na presença de clorí drato de hidroxilamina, ácido formico, EDTA, e extração com to lueno. Uma sensibilidade em torno de 0,25 ppm de selênio foi atingida.

Modificando o método descrito por CHENG (1956), KELLEHER e JOHNSON (1961) incorporaram a técnica da diluição isotópica para compensar as perdas que ocorrem durante as análises e aumentar a sensibilidade. Foi realizada a extração com tolueno e a absorbância medida a $420 \mathrm{~nm}$. Os cálculos foram cor rigidos em função do teste de recuperação com o selênio radioativo. 
CHAO e RILEY (1965) descreveram um método baseado no DAB para determinar selênio em água do mar, sedimentos marinhos e organismos marinhos. Foi usada a coprecipitação com hidróxido de ferro (III) a pH $4-6$ para concentrar o selênio e separá-lo de ions interferentes. o ferro e outros cátions foram separados por troca iônica. Foi usada a diluição isotópica para corrigir os resultados devido às perdas que ocorrem duran te a análise. O método apresenta boa sensibilidade uma vez que os autores determinaram selênio em água do mar em torno de 0,4 $\mathrm{PPb}$.

Outro método bastante interessante é proposto por olsoN (1973), baseado na reação do selênio com 2,3-diamino naftaleno após 30 minutos em banho-maria a 50@C e medida da absorbância a $378 \mathrm{~nm}$. O método é adequado para amostras de plantas contendo mais que 2 ppm de selênio ou na diagnose de toxicidade do selênio em gado, pela análise de pelos.

\subsubsection{Fluorimétricos}

Apesar de se poder determinar fluorimetricamente o selênio com O DAB (WATKINSON, 1960; DYE et alii, 1963), o mé todo fluorimetrico utiliza principalmente o 2,3-diaminonaftale no (DAN) devido à maior estabilidade do reagente e à boa sensi bilidade que é alcançada.

PARKER e HARVEY (1962) foram os primeiros investigadores da reação do ácido selênico com orto-diaminas aromáticas. Mostraram que o selênio reage com DAN em meio ácido, formando o composto fluorescente "4-5-benzopiazselenol", e pode ser extraido da fase aquosa com solventes orgânicos e usado para determinar quantidades abaixo de 0,002 $\mu$ ge selênio. DAN 
é considerado mais sensivel que o DAB na determinação Eluorimé. trica do selênio. O DAB contén dois pares de grupos de ortodia minas, dos quais apenas um reage com selênio sob as condiçōes do experimento, resultando no "Piazselenol" que ainda é fortemente básico e pode ser extraido da fase aquosa por solventes orgânicos apenas com a elevação do $\mathrm{pH}$ da solução. Isto complica o procedimento analítico na presença de metais em que seus hidróxidos são precipitados em soluções neutras ou alcalinas , e necessita sua remoção ou adição de adequados agentes complexantes, os quais têm que apresentar um elevado grau de proreza. LOTT et alii. (1963) descreveram a determinação de miligramas, microgramas e submicrogramas de selênio por gra vimetria, espectrofotometria e fluorimetria, respectivamente, com o DAtr. Empregaram agentes mascaradores para aumentar a seletividade, de tal forma que o selênio pudesse ser determinado na presença de telurio, cobre, zinco, aluminio e outros ions. Concluiram que o procedimento fluorimétrico é cerca de dez vezes mais sensivel que o espectrofotométrico quando se emprega DAN como reagente, embora seja mais susceptível aos interferen tes do que o DAB. Os autores salientam que a reação entre o selênio e DAN é influenciada pela concentração do ácido, tempe ratura, cinética de formação da cor e presença de ions interfe rentes.

CUKOR et alii (1964) desenvolveram um método para determinar selênio em materiais vegetais, usando DAN como reagente e extração com ciclohexano. As reações com diaminas aromáticas são discutidas e a técnica da diluição isotb́pica é apresentada como fator de correçẽo dos possiveis erros cometidos no procedimento analitico. o autor apresenta ainda uma tabela em que compara as propriedades ópticas de vários reagen- 
tes. Para o DAN há un comprimento de onda de fluorescência a $423 \mathrm{~nm}$ e de excitação a $336 \mathrm{~nm}$ e, para o complexo se-DAN o comprimento de onda de fluorescência é de $520 \mathrm{~nm}$ e de excitação $377 \mathrm{~nm}$.

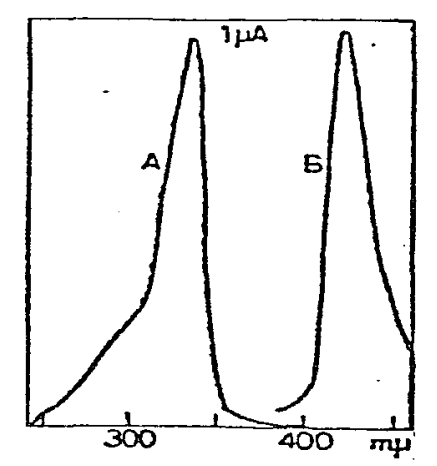

(A) Espectro de excitação do DAN

(B) Espectro de fluorescência do DAN



(C) Espectro de excitação do Se-DAN

(D) Espectro de fluorescência do Se-DAN 
Seguindo o procedimento descrito por PARKER e HARVEY (1962) e CUKOR et alii (1964), ALLAWAY e CARY (1964) coprecipitaram selênio com arsênico, para isolá-lo dos ions inter ferentes. Após, dissolveram o precipitado em $\mathrm{HNO}_{3}{ }^{\text {, fizeram a }}$ reação com DAN adicionando hidroxilamina para minimizar a oxida ção do DAN durante a reação, e mediram a fluorescência em decalina. Os resultados obtidos concordaram com os da análise por ativação neutrônica e o método foi adaptado para uma grande variedade de materiais sem problemas de interferências.

WATKINSON (1966) descreveu um método para a deter minação de baixas concentrações de selênio em várias amostras biológicas, baseando-se na reação com DAN. A perda durante a digestão em ácidos nítrico e perclórico foi de 2,4\%. Verificou que aquecimento vigoroso e prolongado do digerido de ácido perclórico, pode promover a oxidação do selênio (IV) para selênio (VI). Por esta razão, é recomendado normalmente, que o digerido final seja aquecido com uma pequena quantidade de ácido clorídrico concentrado, antes da adição de DAN, a fim de reduzir selenato, que possa estar presente, para selenito. o método foi comparável aos procedimentos de frasco de combustão, separação por ditiol e ativação neutrônica.

EWAN et alii (1968) combinaram um método fluorimé trico para a determinação de baixas concentrações de selênio em pregando digestão por via úmida, coprecipitação de selênio com trióxido de arsênico e reação com DAN. Através deste procedimen to a recuperação do selênio foi de $95 \%$, conforme indicaram testes empregando o radioisótopo ${ }^{75}$ se. Quando selenito foi adicionado a materiais vegetais a recuperação foi de 103\%. Foram obtí das concordâncias satisfatórias entre este e outros métodos ana líticos na estimativa de selênio em amostras contendo 0,01 Ppm 
de selênio.

HOFFMAN et alii(1968) apresentaram um método preciso e relativamente rápido para a determinação de selênio na faixa de nanogramas. Ions interferentes são complexados com EDTA, e o selênio com DAN. Após extração com ciclohexano e centrifugação o teor de selênio é medido fluorimetricamente. As amostras são digeridas com ácidos nitrico, perclórico e sulfúri co e peróxido de hidrogênio.

OLSON (1969) modificou o método de WATKINSON (1966) de determinação de selênio em materiais biológicos. o mé todo também se baseia na digestão por via úmida com ácidos nitrico e perclórico, e medida da fluorescência do "piazselenol " formado após reação com DAN. A sensibilidade está em torno de $0,02 \mu \mathrm{g}$ de selênio.

IHNAT (1974b) realizou um estudo em colaboração com outros laboratórios para determinar selênio fluorimetricamente com DAN em alimentos. Dezenove laboratórios descreveram os resultados analiticos de 10 amostras representativas de vege tais, produtos de laticiaio, carne e peixe. A precisão e exatidão do procedimento foram considerados aceitáveis e o método foi oficializado pela AOAC (Association of official Analytical Chemists).

OLSON et alii (1975) modificaram o primeiro método fluorimétrico para selênio em plantas, da AOAC, para torná10 mais simples e preciso. Também goi alterada a preparação da solução de DAN para deixá-la estável por várias semanas. Este método é comparável ao método oficial e aplicado a uma grande variedade de materiais.

CHAN (1976) melhorou o método fluorimétrico de determinação de selênio em vegetais descritos por ALLAWAY e 
CARY (1964), WATKINSON (1966) e HOFFMAN (1968). Tons interferen tes foram complexados com EDTA e o selênio complexado com DAN é extraido com n-hexano. Estudos de recuperação foram efetuados com a adição de quantidades conhecidas de selênio a 0,50 gramas de amostra vegetal e os resultados foram satisfatórios. As amos tras foram digeridas com uma mistura de ácidos nítrico e percló rico.

JOHNSON et alii (1976) modificaram o método descrito por WATKINSON (1966) e determinaram selênio em tecidos de fígado de amostras representativas da população da Nova Zelândia. A digestão do material foi feita com mistura de ácidos nítrico e perclórico.

\subsubsection{Espectrométricos de absorção atômica}

A $196 \mathrm{~nm}$, linha de ressonância mais sensivel do selênio, sua determinação por absorção atômica é geralmente pos sivel apenas em plantas que acumulam este elemento. A maior van tagem é que se trata de um método rápido e praticamente livre de ions interferentes, porém, tem a desvantagem de trabalhar com pequenos comprimentos de onda, como $196 \mathrm{~nm}$, região que ocor re absorção de luz pela chama de gases.

vários autores trabalharam com a linha de resso nância a 196. ño. RANN e HAMBLY (1965) utilizaram uma chama de ar-acetileno e obtiveram uma sensibilidade em tormo de 1 ppm de selênio. CHAKRABARTI (1968) verificou que a chama ar-acetile no foi mais sensivel que a chama ar-hiđarogênio. NAKAHARA et alii (1970) utilizando a chama ar-hidrogênio para determinar selênio em enxofre, verificaram que o enxofre dá um pequeno efeito de "background" interferindo na análise do selênio. 
o selênio foi determinado por espectrometria de enissão atômica por KIRKBRIGHT et alii (1973) com um limite de detenção até 0,11 ppm de selênio. Com o tipo de instrumentação usada é recomendada a determinação de selênio a 196,09 $\mathrm{nm}$ para minimizar as interferências espectrais.

CHAMBERS e MCCLELIAN (1976) testaram vários solventes orgânicos visando um aumento na sensibilidade de determi nação de selênio. Verificaram que o tetracloreto de carbono e clorofórmio, solventes mais usados na extração de metais, não são convenientes devido às suas características de combustão Ainda, a sensibilidade do selênio na absorção atômica ê melhor em meio aquoso.

Segundo FIORINO et alii (1976) a espectrometria por absorção atômica não é adequada para a determinação direta de selênio. Como a principal linha de ressonância permanece na região do ultravioleta, muitos pesquisadores preferem reduzir o selênio para o seu hidreto antes de introduzir na chama.

Para determinar selênio em material biológico, IHNAT (1976) utilizou o atomizador de formo de grafite e obteve um limite de detecção de $25 \mathrm{ppm}$ de selênio. As amostras foram digeridas com ácidos nitrico, perclórico e sulfúrico e as inter ferências eliminadas por precipitação do selênio com ácido ascórbico. A incorporação de niquel nas soluçọes melhorou a preci são do método, porque o niquel minimizou as perdas de selênio por volatilização.

CLINTON (1977) descreveu um método de rotina de determinação de selênio em plantas na faixa de 0,01 a 0,50 ppm de selênio. As amostras foram digeridas com ácidos nitrico e perclbrico $(5+2)$, reagidas com uma solução aquosa de borato de sódio e resultando no hidreto de selênio. Nos testes de re- 
cuperação obteve-se uma média de $100,5 \%$ e um coeficiente de variação de $4,7 \%$.

\subsubsection{Outros Métodos}

são discutidos de um modo geral outros métodos que também são empregados na determinação quantitativa do selênio.

DANS e HOSTE (1968) desenvolveram um método de análise por ativação neutrônica para a determinação simultânea de telúrio, selênio, arsênico e antimonio em solução eletrolíti ca de sulfato de zinco. Selênio foi separado quimicamente por extração com tolueno após ter reagido com DAN. 0 isótopo ${ }^{75} \mathrm{se}$ foi medido pela técnica de coincidência de raios gama e permitiu a determinação de 0,002 ppm de selênio.

NADKARNI e HALDAR (1971) desenvolveram um método para determinar selênio em análise por ativação neutrônica atra vés da extração subestequiométrica deste elemento com DAB. Vários solventes orgânicos foram testados como extratores do complexo Se-DAB. Concluiram que metil etilcetona e acetato de etila foram os melhores extratores $e$, devido a menor solubilidade deste taltimo na água, foi escolhido como o mais adequado. 0 selênio foi determinado em amostras minerais e vegetais através da reação ${ }^{74}$ Se $(n, \gamma)^{75}$ se e medida posterior das radiações emitidas pelo ${ }^{75} \mathrm{se}$. As amostras minerais foram digeridas com uma mistura de $\mathrm{HNO}_{3}+\mathrm{H}_{2} \mathrm{SO}_{4}+\mathrm{HF}$ e as amostras vegetais com uma mis tura de $\mathrm{HNO}_{3}+\mathrm{HClO}_{4}$.

YOUNG e CHRISTIAN (1973) determinaram selênio por cromatografia gasosa fazendo reagir com DAN, ajustando o $\mathrm{pH}$ a 2 e extraindo o complexo Se-DAN com hexano. o método foi aplicado em amostras de sangue e urina humana, encontrando-se valores mé 
dios de 0,380 e 0,007 $\mathrm{pPm}$ de selênio, respectivamente. 0 tempo completo para análise de uma lanica amostra gira em torno de 3 horas, incluindo o tempo para digestão e 2 horas para formação do complexo.

Usando a análise de emissão molecular em cavidade (MECA *) BELCHER et alii (1974) determinaram de 0,4 a $4 \mu \mathrm{g}$ de selênio. O selênio em misturas orgânicas foi determinado após a decomposição das amostras em frascos de combustão. Também foram descritas a determinação de selênio em misturas inor gânicas. Os ions metálicos interferentes foram eliminados atra vés da redução do selênio ao estado elementar, filtração em $\mathrm{Pa}$ pel de fibra de vidro e direta incorporação do filtro na cavidade.

HOEDE et alii (1975) discutiram uro método de rotina para a deterrainação de baixas concentrações de selênio em materiais orgânicos. o procedimento consiste na produção do ${ }^{75}$ Se $\left(T=120 d\right.$ ) por ativação neutrônica e extração do $\mathrm{SeI}_{4}$ em $\mathrm{CCI}_{4}$. 0 limite de detecção é de aproximadamente $0,010 \mathrm{Ppm}$ de selênio para $500 \mathrm{mg}$ de amostra.

Face a esta revisão de literatura foi escolhido o método fluorimétrico de determinação de selênio para fazer o aprimoramento visando introduzí-1o em análises de rotina. o mé todo colorimétrico com $\mathrm{DAB}$ tem menor sensibilidade que o fluori métrico com DAN e o reagente DAB tem que ser recém-preparado ; o espectrométrico de absorção atômica apresenta interferência de absorção na baixa linha de ressonância do selênio, 196 nm, não alcança boa sensibilidade e pode ocorrer combustão dos sol ventes orgânicos utilizados no processo de extração; não é qual quer laboratório que pode dispor de equipamentos tão caros e 
sofisticados como os usados em análise por ativação neutrônica; enfim, o método fluorimétrico é o que apresenta as melhores van tagens dentre todos os analisados.

3.2. Decomposição de Amostras

De um modo geral, a escolha de un ou outro método de digestão a ser utilizado, depende do elemento a sèr determinado e, da natureza da amostra a ser digerida, da precisão, exa tidão, simplicidade, rapidez e custo operacional. os métodos mais utilizados para digestão de amostras biológicas são: diges tão por via úmida com ácidos concentrados; digestão por via seca; §rasco de combustão a oxigênio; bomba Parr; bomba calorimétrica, etc. (MASSON, 1976).

A grande vantagem da decomposição por via seca $\varepsilon$ que grandes quantidades de material podem ser mineralizados e não requer constantes supervisões por parte do operador. Por outro lado, o processo é demorado. Perdas por volatilização são mais comuns por este método, especialmente para antimonio, arsê nico, cádmio, chumbo, cobre, cromo, estanho, mercúrio, prata e selênio. A extensão destas perdas depende da temperatura e do tempo utilizado para obter a cinza e, em alguns casos das combi nações químicas do elemento que esta presente na amostra. Tempos excessivos de incineração aumentam a possibilidade de conta minação no forno (CROSBY, 1977).

A principal vantagem do método de digestão por via úmida \& que pode ser aplicado a uma grande variedade de materiais, é rápido e menos sujeito a perdas, tanto por volatilização como por retenção pelas cinzas. o método é limitado pela quantidade de amostra, requer constantes supervisões e elevado consumo de reagentes (CROSBY, 1977). 
WATKINSON (1960) relata um procedimento de diges tão de material vegetal com ácidos nítrico e perclórico, onde uma quantidade de material finamente moído, contendo não menos que $0,02 \mu \mathrm{g}$ de selênio é deixada por uma noite com $10 \mathrm{ml}$ de ácido nítrico, e logo após efetuada a digestão. Quando a maioriá do material está digerida são adicionados $5 \mathrm{ml}$ de ácido perclórico e promovido o refluxo.

FEIGL (1961) descreve o uso de persulfato de potássio e ácido sulfúrico na presença de nitrato de prata como catalizador, para a digestão de amostras. Verificou que a combinação da decomposição oxidativa com ácido perclórico, e a reação de రxxido-redução entre o ácido selênico resultante e a hidrazina pode levar a um teste especifico para o selênio, uma vez que o ácido perclórico não reage com hidrazina en meio aquoso.

CUMMINS et alii (1964); YOUNG e CHRISTIAN (1973). e HOLYNSKA e LIPINSKA-KALITA (1977) relatam o uso de uma solução digestora a base de molibdato de sódio, ácidos sulfurico e percl6rico, na digestão de materiais biológicos para a determi nação de selênio. São digeridos cerca de 1,0 grama de amostra em 10 a $20 \mathrm{ml}$ de solução digestora com temperatura não superior a 170C para não haver perdas de selênio por volatização.

0 método do erasco de combustão a oxigênio não é adequado para grandes quantidades de material, o que muitas vezes e exigido devido aos baixos níveis de selênio que são en contrados nos materiais a serem analisados (CROSBY, 1977). De uma forma geral até 1,0 grama de matéria seca (com até $30 \%$ de umidade) pode ser decomposta por este método.

Utilizando o frasco de combustão a oxigênio GOTENMANN e IISK (1961) deterninaram selênio em amostras de aveia. 
A combustão em um sistema fechado eliminou as perdas de selênio por volatilização tomando a determinação mais simples e sensivel, e a recuperação foi da ordem de 90\%. DYE et alii (1963): ALLAWAY e CARY (1964); CUKOR et alii, (1964) e WATKINSON (1966) também utilizaram o frasco de combustão a oxigênio.

MASSON (1976) comparou a decomposição de compostos orgânicos pelo método do frasco de combustão a oxigênio com - método de decomposição por via úmida usando ácidos nítrico e sulfúrico. Verificou que o método do frasco de combustão a oxigênio é mais simples, rápido, requer apenas equipamentos baratos e sua temperatura de combustão de 1100 - 1200ㄷ destroi qua se todos os compostos orgânicos e produz o se (IV). A desvantagem da digestão por via úmida é que compostos de Se (VI) não po dem ser analisados com sucesso porque ele não é reduzido a se (IV) como acontece no frasco de combustão a oxigênio e-o se(VI) não reage com DAN.

Para a determinação fluorimétrica de selênio foram selecionados os métodos de digestão por via úmida (nitricoperclórica e sulfo-perclórica) e por via seca com o frasco de combustão a oxigênio. 


\section{4 - MATERIAI E METODOS}

\subsection{MATERIAL}

4.1.1. Instrumentos e Acessórios

- Fluorimetro TURNER modelo 110, equipado com Piltro primário no 7 - 60 (365 nm) e combina ção de filtros secundários no 58 (525 nm) e no 2A-15 (520 $\mathrm{nm})$.

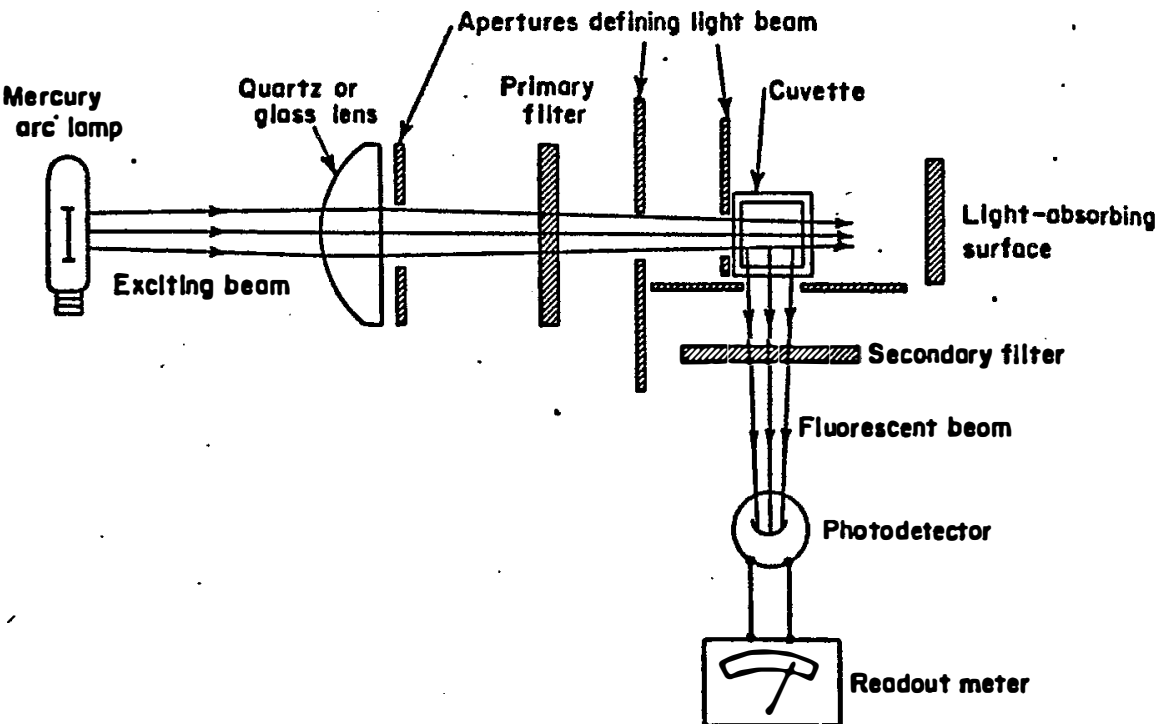

Diagrama esquemático dos componentes bpticos de un fluorimetro tipico(extraido de VILIARD, H.H. et alii, 1965). 
- Um fluorimetro consiste principalmente de uma fonte de radiação que produz a energia necessá ria para excitar a amostra a um estado de maior energia, e uma unidade monocromadora que permi te apenas à fluorescência emitida ser captada pelo detector. Normalmente é usado como fonte de luz de excitação a radiação na região do ul travioleta, tais como, as lâmpadas de hidrogênio, mercúrio ou arco de xenônio. Radiação monocromática é obtida tanto por meio de filtros ou monocromadores.

o filtro primário seleciona o comprimento de onda que vai excitar a amostra, o secundário seleciona aquele específico da fluorescência da amostra.

Daí o processo de fluorescência ser caracterizado por dois espectros: de excitação e de flū orescência.

- Espectrômetro gama monocanal ortec, constituido por um cristal NaI(TI) de $3 \times 3$ pol., tipo poço ( 1 1/2 pol. de profundidade e $7 / 8$ pol. de diâmetro) e demais componentes.

- Potenciômetro RADIOMETER-COPENHAGEN modelo 63, equipado com eletrodos de vidro, tipo G 202C , e calomelano, tipo $\times 401$.

- Blocos digestores TECHNICON Modelo BD-40, equi pados com tubos de digestão aferidos para $75 \mathrm{ml}$. 


\subsubsection{Vidrarias Especiais}

Além de vidraria de uso comum em laboratório de quimica analitica foram usados:

- Frasco de combustão a oxigênio (schơniger)cons tituido de balão de fundo chato de $2.000 \mathrm{ml}$ com saída lateral, fêmea de 55/50, macho de vî dro esmerilhado de 55/50 com adaptação para o suporte das amostras (KRUG, 1975).

- Funis de separação de $125 \mathrm{ml}$, tipo SQUIBB, for ma pera, com tomeira de Teflon e tampa de polietileno.

4.1.3. Reagentes e Soluções Todos os reagentes foram de qualidade próanálise:

- Azul de Timol

- Ciclohexano

- Cloridrato de hidroxilamina

- 2,3-diaminonaftaleno

- Etilenodiaminotetracetato dissódico

- Hidróxido de amônio

- Molibdato de sódio

- Selênio em pó negro 
Todas as soluções foram preparadas com água desmineralizada:

- Solução estoque de ${ }^{75}$ se:

o selênio radioativo ( $\left.{ }^{75} \mathrm{Se}\right)$, produzido pela New England Nuclear, foi comprado em duas épo cas diferentes, com as seguintes caracteristicas (2a remessa):

Radioisరtopo: ${ }^{75} \mathrm{Se}$

Composição química: ácido selenoso em HCl 0,5M. Atividade: $5 \mathrm{mCi}$

Volume: $0,1 \mathrm{ml}$

Atividade/volume: $50 \mathrm{mCi} / \mathrm{ml}$

Atividade especifica: $185,2 \mathrm{mCi} / \mathrm{mg}$ Se

Esta solução foi transferida para um balão volumétrico de $50 \mathrm{ml}$ e diluida com água até o vo lume, apos sucessivas lavagens do frasco origi nal. Características desta solução: $540 \mathrm{ng} / \mathrm{ml}$ de se e $100 \mu \mathrm{Ci} / \mathrm{ml}$.

- Solução de ${ }^{75}$ se de $20 \mu \mathrm{g} / \mathrm{ml}$ de se e $1 \mu \mathrm{Ci} / \mathrm{ml}$ : Esta solução foi preparada transferindo-se $1 \mathrm{ml}$ da solução estoque de ${ }^{75}$ se e $20 \mathrm{ml}$ de uma solü ção de selênio estável de $100 \mu \mathrm{g} / \mathrm{ml}$ de se (car regador) para un balão volumétrico de $100 \mathrm{ml}$. Apठs, a mistura foi diluida ao volume desejado com $\mathrm{H}_{2} \mathrm{SO}_{4} \mathrm{O}, 01 \mathrm{~N}$.

- Soluções de trabalho de ${ }^{75}$ se:

A partir da solução de $20 \mu \mathrm{g} / \mathrm{ml}$ de se foi preparada uma solução de $2 \mu \mathrm{g} / \mathrm{ml}$ de se e, por diluições adequadas desta ultima, padrões de 
${ }^{75}$ Se na faixa de 0,05 a $1,00 \mu \mathrm{g} / \mathrm{ml}$ de se.

- Solução estoque de selênio estável de $100 \mu \mathrm{g} / \mathrm{ml}$ de Se:

Adicionaram-se lentamente $5 \mathrm{mI}$ de $\mathrm{HrO}_{3}$ concentrado em $50 \mathrm{ml}$ de água. Nesta mistura dissol veu-se $0,1 \mu \mathrm{g}$ de selênio a quente (selênio com 99,9\% de pureza). Adicionaram-se $20 \mathrm{ml}$ de solu ção ácido sulfarico $5 \mathrm{~N}$ à mistura e completouse o volume a $1000 \mathrm{ml}$ com água.

- Soluções de trabalho de selênio estável:

Foram preparadas por diluições adequadas da so Iução estoque de $100 \mu \mathrm{g} / \mathrm{ml}$ de Se, adicionandose volumes definidos de $\mathrm{H}_{2} \mathrm{SO}_{4} \mathrm{O}, 1 \mathrm{M}$, de forma a se obter padrões de selênio na faixa de 0,01 a $1,00 \mathrm{jg} / \mathrm{ml}$ de Se em $\mathrm{H}_{2} \mathrm{SO}_{4} 0,01 \mathrm{~N}$.

- Solução de DAN $4 \times 10^{-3} 3^{4}$ :

Em funil de separação de $250 \mathrm{ml}$, foram dissol_, vidos 0,0791 $\mathrm{g}$ de DAN em $125 \mathrm{ml}$ de $\mathrm{H}_{2} \mathrm{SO}_{4} 5 \mathrm{~N}$, após agitação da mistura por 15 minutos. Adici onaram-se $50 \mathrm{ml}$ de ciclohexano e agitou-se por 5 minutos. Ap $\delta$ s as fases separarem inseriu-se lã de vidro na saida do funil e transferiu-se a fase aquosa para outro funil, descartando-se a fase orgânica. Repetiu-se a extração por mais duas vezes e, após a terceira extração transferiu-se a fase aquosa para um frasco de vidro de baixo actínico e adicionou-se uma camada de hexano sobre a solução para evitar o contato com $o$ ar e haver sua degradação e arma 
zenou-se em refrigerador. Esta solução é estável por várias semanas (IHNAT, 1974 a).

\subsubsection{Amostras}

\subsubsection{Material Vegetal}

Foram utilizados feno de grama Estrela ( Gynodon. plectostachyus), silagem de milho (zea mays) e dois tipos de mistura de alimento concentrado: um contendo em torno de 2,6 e o outro 0,1 ppm de selênio, obtidos no Departamento de Zootec nia da ESALQ. (A denominação de alimento concentrado se refere a uma ração de elevado teor proteico, composto de milho, fare10 de soja e algodão, sais minerais e vitaminas).

\subsubsection{Soro de Sangue}

Foram tomadas amostras individuais de $20 \mathrm{ml}$ de sangue da veia jugular de touro. Apరs coagulação do sangue à temperatura ambiente este foi centrifugado a $2.000 \mathrm{rpm}$ por 5 minutos e separadas as porções soro e fração figurada, sendo ambas guardadas a -20C até o momento da determinação do teor de selênio. Maiores detalhes a respeito das caracteristicas das amostras podem ser encontrados no trabalho publicado por CARDO so (1978).

4.2. METODOS

4.2.1. Metodologia de Detecção de ${ }^{75} \mathrm{Se}$

Segundo BALIAUX et alii (1968) ${ }^{75}$ se decai por captura eletrônica (C.E.) formando um núcleo de ${ }^{75}$ As estável. 
A meia vida física do ${ }^{75}$ Se é de $120 ; 4$ dias (LEDERER et alii, 1967). A Figura 1 mostra o esquema de desintegração do ${ }^{75} \mathrm{se}$, com as respectivas energias em $\mathrm{KeV}$ (mil elétrons volts) das radiações gama emitidas, extraido de BALLAUX et alii (1968).

Segundo LEDERER et alii (1967) as energias aproximadas do raio gama do decaimento do ${ }^{75} \mathrm{Se}$, em MeV, e suas res pectivas intensidades, como raios gama, são: 0,066 (1,0\%); $0,097(3,3 \%) ; 0,121(17,0 \%) ; 0,136(57,0 \%) ; 0,265(60,0 \%)$; $0,280(25,0 \%)$ e $0,401(12,0 \%)$.

4.2.1.1. Espectro de Raios Gama de ${ }^{75} \mathrm{se}$

Com a finalidade de se definir a melhor região do espectro do ${ }^{75}$ se para determinação das atividades das amostras, a alta tensão do espectrômetro gama foi fixada em 1000 volts (voltagem compativel com a fotomultiplicadora), fixou-se - ganho do amplificador (ganho grosso = 100 e ganho fino=0,834) e $1,0 \mathrm{ml}$ de solução de $10 \mathrm{nCi} / \mathrm{ml}$ foi transferida para um tubo de contagem e colocado no interior do cristal de NaI ativado com tálio, tipo poço, protegido por um castelo de chumbo para minimizar a taxa de contagens da radiação de fundo:

As leituras em impulsos por segundo foram obtí das variando-se a voltagem de base no analisador com uma abertura constante na janela de 0,1 volt, sendo o tempo para cada leitura de 12 segundos.

4.2.1.2. Efeito da Geometria das Amostras na de-
tecção de ${ }^{75} \mathrm{Se}$

o efeito da geometria das amostras na deteç̧ão de ${ }^{75}$ se foi verificado de acordo com o procedimento descrito por KRUG (1975). Foi transferido $1 \mathrm{ml}$ de uma solução contendo $10 \mathrm{nCi} / \mathrm{ml}$ para un tubo de contagem e as amostras preparadas 


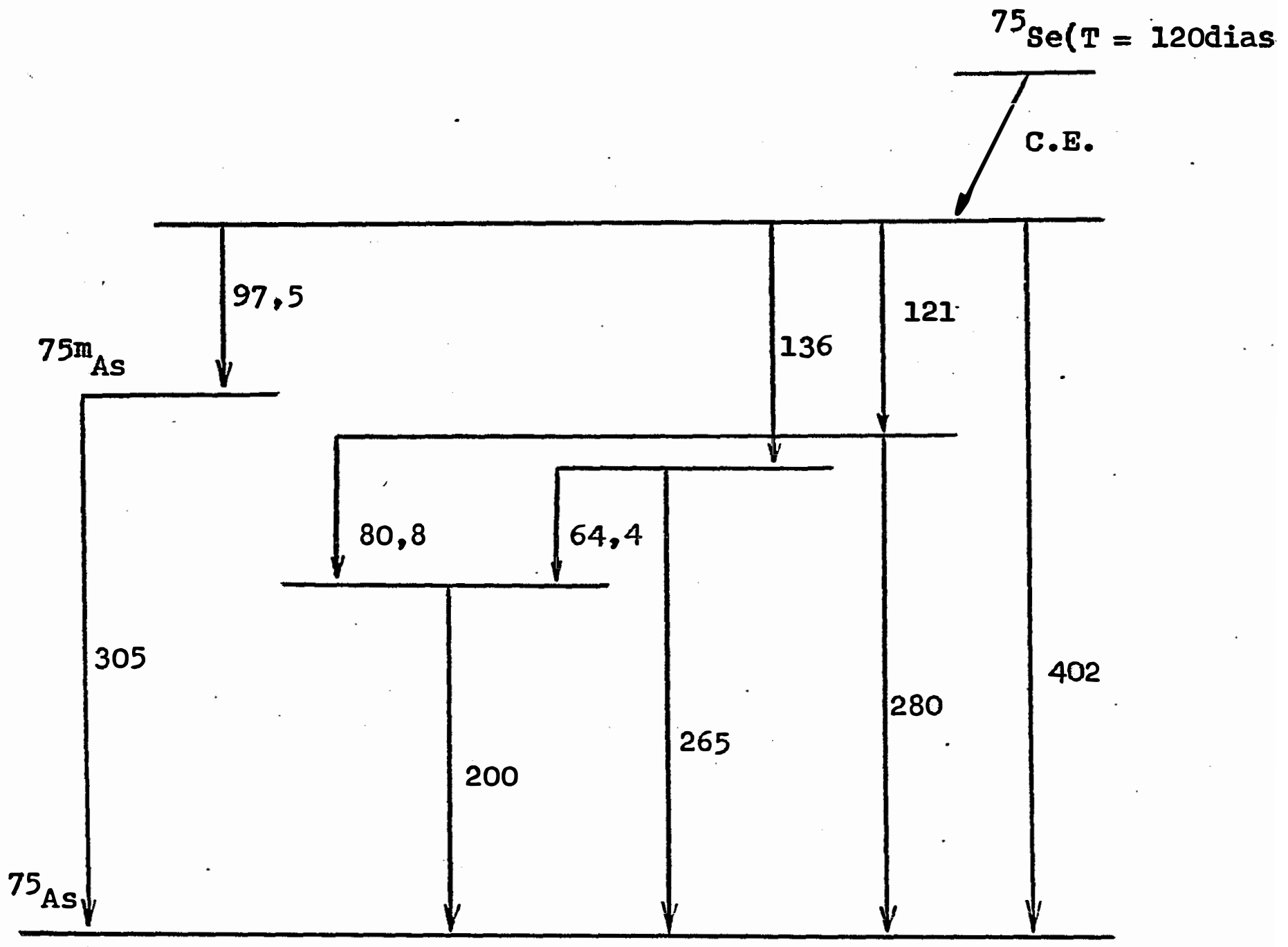

FIGURA 1. Esquema de desintegração do ${ }^{75}$ se (BALLAUX et alii, 1968). 
por diluição com água no próprio tubo de contagem, adicionando se de 0 a $19 \mathrm{ml}$ de água, de 1 en $1 \mathrm{ml}$.

Em função dos resultados obtidos en 4.2.1.1. foi definida a região do espectro de ${ }^{75}$ se para se proceder às contagens.

Segundo KRUG (1975), considerando-se somente o efeito da geometria, quando se quer correlacionar as atividades de duas amostras, com volumes diferentes, a correção das taxas de contagem é imprescindível.

Nos experimentos subsequentes foram feitas as de vidas correções, a fim de padronizar as amostras, evitandose desta forma que a geometria da mesma influisse nos resultados obtidos.

\subsubsection{Decomposição de Amostras}

Através de uma análise crítica dos métodos de decomposição de materiais vegetais e tecidos animais, descritos na literatura (vide 4.2.), foram selecionados três procedimentos para obtenção dos extratos a serem analisados.' Esta esco Iha baseou-se na precisão, exatidão, simplicidade, rapidez e custo de cada procedimento.

Convém lembrar que os métodos de decomposição por via umida foram testados em blocos digestores, de tal forma que até 40 digestões simultâneas pudessem ser realizadas.As sim sendo, pequenas modificcações nos métodos originais foram feitas.

4.2.2.1. Via Umida com Ácidos Nitrico e Perclóri co

o método de decomposição das amostras com ácidos 
nitrico e perclorico concentrado foi adaptado de olson (1969 e 1973) e testado conforme o seguinte procedimento:

a) Transferir $1 \mathrm{ml}$ de soro de sangue (ou $500 \mathrm{mg}$ de material vegetal seco e moido) para tubo de digestão de $75 \mathrm{ml}$.

b) Adicionar $1 \mathrm{ml}$ de solução padrão de ${ }^{75} \mathrm{se}$ na faixa de 0,05 a 1,00 ppm de selênio, na presença e na ausência das amostras.

c) Adicionar $5 \mathrm{ml}$ de $\mathrm{HNO}_{3}$ concentrado e $2 \mathrm{ml}$ de $\mathrm{HClO}_{4}$ 70\% (para material vegetal, após adição de $\mathrm{HNO}_{3}$ e $\mathrm{HClO}_{4}$, deixar a mistura em repouso por uma noite ou cerca de 12 horas).

d) Levar os tubos para o bloco digestor e decompor as amostras inicialmente a 1600C e elevar a temperatura para 210 oc e deixar até aparece rem os fumos de $\mathrm{HClO}_{4}$, e aquecer por mais 15 minutos.

e) Retirar os tubos do bloco digestor e deixar esfriar por 10 minutos.

f) Adicionar $2,5 \mathrm{ml}$ de $\mathrm{HCl}(1+9)$ e colocar em banho-maria a 90ㄷ por 30 minutos. Colocar fü nis na boca dos tubos para dar refluxo. Retirar e deixar esfriar.

A avaliação do método de decomposição foi feita através da análise de selênio nos extratos, tanto por fluorime tria como pela análise de ${ }^{75}$ se, após extração do complexo seDAN, de acordo com o seguinte procedimento: 
g) A solução obtida no (tem f), adicionar $5 \mathrm{ml}$ de EDTA $0,02 \mathrm{~N} ; 1 \mathrm{ml}$ de cloridrato de hidroxi lamina $20 \%$ e agitar.

h) Adicionar $5 \mathrm{ml}$ de DAN $4 \times 10^{-3} \mathrm{M}$.

i) Adicionar 3 gotas de Azul de Timol 1\% (ate cor rósea), neutralizar con $\mathrm{NH}_{4} \mathrm{OH} 6 \mathrm{~N}$ (até cor amarela) e deixar reagindo em banho-maria a 70 ec por 60 minutos.

j) Transferir a solução para funil de separação de $125 \mathrm{ml}$ e adicionar $5 \mathrm{ml}$ de ciclohexano.

k) Proceder a extração por 15 segundos.

1) Descartar a fase aquosa e analisar $4 \mathrm{ml}$ da $\mathrm{fa}$ se orgânica por fluorimetria e espectrometria gama.

Para análise por fluorimetria fazer a leitura contra o padrão 0,00 ppm de selênio, em fluorimetro com excita ção a 366 nm e deteç̧ão da fluorescência a 525 nm.

4.2.2.2. Via Ómida com Acidos Sulfúrico e Perclo rico

o método de decomposição de amostras com ácidos sulfúrico e perclórico concentrados foi adaptado de HOLYNSKA e IIPINSKA-KALTTA (1977), e testado conforme o seguinte procedimento:

a) Transferir $1 \mathrm{ml}$ do soro de sangue (ou $600 \mathrm{mg}$ de material vegetal seco e moido) para Erlenmeyer de $125 \mathrm{ml}$. 
b) Adicionar $1 \mathrm{ml}$ de solução padrão de ${ }^{75} \mathrm{se}$ na faixa de 0,05 a 1,00 ppm de selênio, na presença e na ausência de amostras.

c) Adicionar $20 \mathrm{ml}$ de solução digestora (Preparo: dissolver $10 \mathrm{~g}$ de molibdato de sódio em 150 $\mathrm{ml}$ de $\mathrm{H}_{2} \mathrm{O}$ e adicionar $150 \mathrm{ml}$ de $\mathrm{H}_{2} \mathrm{SO}_{4}$ concentrado. Apठs esfriar, adicionar $200 \mathrm{ml}$ de $\mathrm{HClO}_{4}$ $70 \%)$.

d) Levar à placa aquecedora e aquecer por $45 \mathrm{~min}$. A temperatura foi controlada e não excedeu a 1609C. Esfriar.

e) Completar o volume a $50 \mathrm{ml}$ com água.

A avaliação do método de decomposição foi feito através da análise de selênio nos extratos, tanto por fluorimetria como pela análise de ${ }^{75}$ se, após extração do complexo seDAN, de acordo com o seguinte procedimento:

f) Corrigir $\circ \mathrm{PH}$ para 2-2,5, com $\mathrm{NH}_{4} \mathrm{OH}$ concentra do.

g) Adicionar $1 \mathrm{ml}$ de EDTA $0,1 \mathrm{M}$ e agitar.

h) Adicionar $1 \mathrm{ml}$ de cloridrato de hidroxilamina $5 \%$ e agitar.

i) Adicionar $1 \mathrm{ml}$ de $\mathrm{DAN} 4 \times 10^{-3} \mathrm{M}$ e deixar rea gindo em estufa a 60C por 1 hora. Esfriar.

j) Transferir a solução para funil de separação de $125 \mathrm{ml}$ e adicionar $5 \mathrm{ml}$ de ciclohexano.

k) Proceder a extração por 15 segundos. 
1) Descartar a fase aquosa e analisar 4ml da fase orgânica por fluorimetria e espectrometria gama.

Para análise por fluorimetria, fazer a leitura contra o padrão 0,00 ppm de selênio, em fluorímetro com excita ção a $366 \mathrm{~nm}$ e detecção da fluorescência a $525 \mathrm{~nm}$.

4.2.2.3. Via Seca com Frasco de Combustão de schoniger

Segundo KRUG (1975), a queima de materiais orgânicos em uma atmosfera de oxigênio tem várias vantagens. Ela é rápida, simples e relativamente independente da concentração do elemento que se quer analisar. 0 oxigênio pode ser encontra do com alto grau de pureza, sem maiores problemas de purifica ção, o que normalmente não ocorre com os ácidos minerals utili zados na decomposição das amostras por via umida. Para que a combustão do material seja possível, é necessário que o mesmo não contenha mais que $30 \%$ de umidade.

A avaliação do método de decomposição de materiais vegetais no frasco de combustão foi feita, de acordo com o método proposto por GUTENMANN e IISK (1961), com pequenas modi ficações no tamanho do frasco e no preparo da amostra a ser queimada conforme KRUG (1975):

a) Fazer uma mistura de silagem e bacto-agar na proporção de $4: 1$.

b) Fazer peletes com aproximadamente $1,5 \mathrm{~g}$ da mistura e adicionar 50 ul da solução de $2 \mathrm{ng} /$ $\mu \mathrm{l}$ de ${ }^{75} \mathrm{Se}$.

c) Preparar padrões de ${ }^{75}$ se em balões volumétri- 
cos de 25 a $50 \mathrm{ml}$ : adicionar $50 \mu \mathrm{l}$ da solução de ${ }^{75}$ Se anterior e completar o volume dos baIões.

d) Envolver os peletes em papel e transferir cuidadosamente para a cesta pendurada no macho do frasco de combustão.

e) Pipetar em frascos de combustão separados, 25 e $50 \mathrm{ml}$ de $\mathrm{H}_{2} \mathrm{SO}_{4} 0,0 \mathrm{IN}$ para a absorção dos gases.

f) Colocar um balão de borracha na saída lateral do frasco de combustão.

g) Colocar a barra do agitador magnético dentro do frasco e injetar oxigênio no frasco, de tal forma que a sua atmosfera propicie a combustão.

h) Acender a amostra e inserir cuidadosamente no frasco. Deve-se observar que durante a combustão há expansão dos gases e o balão de borracha é inflado.

i) Ligar o agitador magnético vigorosamente por 10 minutos, o processo termina quando o balão de borracha volta à sua forma original.

j) Transferir $5 \mathrm{ml}$ da solução absorvedora, dos frascos de combustão e dos balões volumétricos, para tubos de contagem e analisar no espectrômetro gama.

k) Efetuar a detecção de ${ }^{75}$ Se nas cinzas. 
4.2.3. Metodologia de Determinação

Uma vez que os métodos descritos na literatura não eram concordantes, tanto na formação do complexo Se-DAN como na extração do complexo com solventes orgânicos, vários expe rimentos foram realizados, visando um melhor conhecimento dos passos analíticos envolvidos na separação do selênio e sua determinação por fluorimetria.

Considerando que extratos de tecidos vegetais e animais serão obtidos por decomposição nítrico-perclórica, a formação do complexo Se-DAN, assim como sua extração, foram ava liadas em fase aquosa obtida de soluções padrões de ${ }^{75} \mathrm{se}$ na ausência de tecidos vegetais e animais, de acondo com o procedi mento descrito em 4.2.2.1. (do item $\underline{b}$ até $\circ \underline{g}$ ). Também foram $u$ tilizados padrões de selênio estável.

As influências de EDTA e $\mathrm{NH}_{2} \mathrm{OH} \bullet \mathrm{HCl}$ não foram testadas, porque os dois reagentes devem estar presentes em excesso, para "mascarar" possiveis interferentes (LOTT et alii,1963; CUKOR et alii, 1964; HOFFMAN et alii, 1968; CHAN, 1976) e evitar uma possivel oxidação do reagente orgânico DAN (ALLAWAY e CARY, 1964).

4.2.3.1. Concentração do 2,3-diaminonaftaleno (DAN)

A maioria dos autores trabalham com DAN em tormo de $6 \times 10^{-3} \mathrm{M}$ para determinar selênio por fluorimetria (PARKER e HARVEY, 1962; LOTT et alii, 1963; ALLAWAY e CARY, 1964; CUKOR et alii, 1964; WATKINSON, 1966; EWAN et alii, 1968; HOFFMAN et alii, 1968; OLSON, 1969; CHAN, 1976)。 
Como as condições do método proposto diferem dos métodos de outros autores, procurou-se saber qual a concentração de DAN que melhor se adaptaria ao novo método. Foi realizado um experimento de acordo com o procedimento descrito em 4.2.2.1., variando-se apenas o item $\underline{h}$. Foram colocadas para reagir $1 \mathrm{ml}$ de cada solução de DAN, com concentrações variando desde $2 \times 10^{-3}$ ate̊ $2 \times 10^{-2} \mathrm{M}$, com 5 soluções padrões de selênio variando desde 0,05 até $1,00 \mathrm{ppm}$ ( $1 \mathrm{ml}$ de cada solução).

4.2.3.2. Efeito do Tempo e Temperatura na Reação Há una certa controvérsia entre os autores quanto ao tempo e temperatura de reação entre selênio e DAN, para determinação de selênio por fluorimetria. Segundo PARKER e HARVEY (1962) deve ser deixada a solução em banho-maria por 20 minutos; LOTT et alii (1963) e CUKOR et alii (1964) recomendam que se deixe a solução em repouso por 2 horas à temperatura ambiente; ALLAWAY e CARY (1964) deixam a solução a 30oC por 90 minutos; WATKINSON (1966) e OLSON (1969) colocam a solução em lugar escu ro em temperatura de 500C por 20-25 minutos; EWAN (1968) deixa. a solução incubada a 50C por 45 minutos e, HOFFMAN et alii (1968) e CHAN (1976) aquecem a solução até a ebulição. Assim sendo, foi realizado um experimento, de acordo com o procedimento descrito em 4.2.2.1., variando apenas o item i. Todos os tratamentos constaram de duas repetições e solução padrão de ${ }^{75}$ se de mesma atividade. Tomando-se por base a temperatura de $300 \mathrm{C}$ e confrontando-a com as temperaturas de $40,50,60,70,80$ e 90 oc variou-se o tempo desde 5 até 240 minutos para cada temperatura. 
4.2.3.3. Influência do Solvente Orgânico

Os solventes orgânicos utilizados na extração do complexo Se-DAN para determinação de selênio por fluorimetria, nem sempre são os mesmos. o solvente decalina foi utilizado por PARKER e HARVEY (1962), ALLAWAY e CARY (1964), EWAN et alii (1968) e OLSON (1969); tolueno por LOTT et alii (1963); ciclohe xano por CUKOR et alii (1964), WATKINSON (1966) e HOFFMAN et alii (1969); o n-hexano por CHAN (1976).

Devido a esta diversidade de solventes orgânicos utilizados, foi realizado um experimento de acordo com o procedimento descrito em 4.2.2.1., variando apenas o item $j$. Foram testados 8 tipos de solventes orgậnicos, os quais se acham rela cionados na Tabela 2. Todos os trätamentos constaram de duas re petições e solução padrão de ${ }^{75}$ se de mesma atividade foi sempre utilizado. 
TABELA 2. Características físicas dos solventes orgânicos utili zados *.

\begin{tabular}{lccc}
\hline Solvente & Ponto de & Densidade & Solubilidade \\
Orgânico & Ebulição $(\underline{\mathrm{oc}})$ & $\left(\mathrm{g} / \mathrm{cm}^{3}\right)$ & em água $(\%)$ \\
\hline
\end{tabular}

Acetato de etila
$\left(\mathrm{CH}_{3} \mathrm{COOCH}_{2} \mathrm{CH}_{3}\right)$
77,1
0,901
6,90

Alcool isoamilico

$\left(\mathrm{CH}_{3}\right)_{2} \mathrm{CHCH}_{2} \mathrm{CH}_{2} \mathrm{OH}$

130,5

0,812

2,67

Metil-isobutil-cetona

$\mathrm{CH}_{3} \mathrm{COCH}_{2} \mathrm{CH}\left(\mathrm{CH}_{3}\right)_{2}$

115,9

0,802

1,91

Tetracloreto de carbono
$\left(\mathrm{CCl}_{4}\right)$
76,7
1,595
0,08

Ciclohexano

$\left(\mathrm{C}_{6} \mathrm{H}_{12}\right)$

80,8

0,780

0,01

Hexano

$\left(\mathrm{C}_{6} \mathrm{H}_{14}\right)$

68,0

0,659

0,01

Benzeno

$\left(\mathrm{C}_{6} \mathrm{H}_{6}\right)$

80,1

0,879

0,18

Clorofórmio

$\left(\mathrm{CHCl}_{3}\right)$

61,2

1,492

0,82

* Dados extraidos de WEAST (1975) e MONTES (1974). 
4.2.3.4. Efeito da razão fase aquosa/fase orgânica

A fim de verificar o melhor volume de solvente or gânico para extrair o complexo se-DAN, realizou-se um experimen to de acordo com o procedimento descrito em 4.2.2.1., variando apenas 0 ítem $j$. Antes da adição do solvente orgânico no funil de separação, foi retirada uma aliquota de $5 \mathrm{ml}$ da fase aquosa de todos os tratamentos para contagem no expectrômetro gama e devolvido aos funis. Mantendo-se constante a fase aquosa, quantidades crescentes de ciclohexano até $6 \mathrm{ml}$ foram adicionados ao funil de separação, a mistura foi agitada por 30 segundos e, após as fases se separarem, a fase orgânica foi coletada, de acordo com a Tabela 3 , para determinar as contagens do ${ }^{75} \mathrm{Se}$. To dos os tratamentos constaram de duas repetições. Repetiu-se o experimento sob as mesmas condições, aumentando o volume do sol vente orgânico até $10 \mathrm{ml}$.

TABELA 3. Tratamentos referentes ao estudo da razão fase aquosa/ fase orgânica (fase aquosa $=21,5 \mathrm{ml}$ ).

\begin{tabular}{cccc}
\hline Tratamento & $\begin{array}{c}\text { fase orgânica } \\
\text { adicionada }(\mathrm{ml})\end{array}$ & $\begin{array}{c}\text { fase orgânica } \\
\text { analisada }(\mathrm{ml})\end{array}$ & $\begin{array}{c}\text { fase aquosa/ } \\
\text { fase orgânica }\end{array}$ \\
\hline 1 & 2 & 1 & 10,75 \\
2 & 3 & 2 & 7,17 \\
3 & 4 & 2 & 5,38 \\
4 & 5 & 2 & 4,30 \\
5 & 6 & 2 & 3,58 \\
\hline
\end{tabular}


4.2.3.5. Cinética de Extração

Uma vez que há muita controvérsia quanto à cinéti ca de extração do complexo Se-DAN por solventes orgânicos, como mostram os dados da Tabela 4, foi realizado um experimento, de acordo com o proceimento descrito em 4.2.2.1. variando apenas o item ‥ Todos os tratamentos constaram de duas repetições, solu ção padrão de ${ }^{75}$ se de mesma atividade e agitação manual.

TABELA 4. Estudo de cinética de extração do complexo se-DAN por diferentes autores

Referência

Solvente orgânico

Tempo de extração

$\begin{array}{llc}\text { PARKER e HARVEY (1962) } & \text { Decalina }(5 \mathrm{ml}) & 1 \text { minuto } \\ \text { LOTT et alii (1963) } & \text { Tolueno }(10 \mathrm{ml}) & 30 \text { segundos } \\ \text { ALLAWAY e CARY (1964) } & \text { Decalina }(10 \mathrm{ml}) & 10 \text { minutos } \\ \text { CUKOR et alii (1964) } & \text { Ciclohexano }(10 \mathrm{ml}) & 5 \text { minutos } \\ \text { WATKINSON (1966) } & \text { Ciclohexano }(10 \mathrm{ml}) & 1 \text { minuto } \\ \text { EWAN et alii. (1968) } & \text { Decalina }(10 \mathrm{ml}) & 7 \text { minutos } \\ \text { HOFFMAN et alii (1968) } & \text { Ciclohexano }(6 \mathrm{ml}) & 5 \text { minutos } \\ \text { OLSON (1969) } & \text { Decalina }(10 \mathrm{ml}) & 30 \text { segundos } \\ \text { CHAN (1976) } & \text { n-hexano }(6 \mathrm{ml}) & 30 \text { segundos }\end{array}$

4.2.3.6. Número de Extrações

De acordo com FRITZ e SCHENK (1976) uma extração é considerada quantitativa quando pelo menos 99,9\% da espécie química de interesse é extraída por um solvente orgânico. Assim sendo, dependendo da espécie química a ser extraída, uma ou 
mais extrações são necessárias para atingir o nível de extração desejado. Com relação ao complexo Se-DAN, CUKOR et alii (1964) recomendam duas extrações sucessivas com ciclohexano, ao passo que WATKINSON (1966) e HOFFMAN et alii (1968) recomendam uma única extração. Segundo DYE et alii (1963) uma única extração é suficiente e não há vantagem em se aumentar o número de extra ções porque o volume da fase orgânica também seria aumentado, com consequente diminuição de sensibilidade.

Devido à não concordância entre certos autores foi realizado um experimento para verificar o efeito do número de extrações, seguindo o procedimento descrito em 4.2.2.1. do ítem $\underline{b}$ até $\circ \underline{k}$. Efetuada a la extração e verificada a atividade do ${ }^{75} \mathrm{Se}$ da fase orgânica, foram adicionados mais $5 \mathrm{ml}$ de ciclohexano à fase aquosä e feita a 2a extração.

Repetiu-se 0 experimento de acordo com $\circ$ mesmo procedimento e foram testados 7 solventes orgânicos diferentes, com duas repetições e solução padrão de ${ }^{75}$ se de mesma atividade.

\subsubsection{Precisão e Exatidão do Método}

A precisão e exatidão do método foram verificadas através da análise química de um material de referência de soro de sangue fornecido pela Agência Internacional de Energia Atômi ca (№ de código: A-2/1974): o valor recomendado pela IAEA '"é $0,59 \pm 0,09 \mathrm{ppm} \mathrm{Se}$, coeficiente de variação = 15\% e não usar me nos que $200 \mathrm{mg}$ de material.

Tanto a precisão como a exatidão do método foram verificadas, segundo dois processos: a) pela curva padrão em so lução aquosa, com quatro repetições, b) através da técnica do padrão intermo, com três repetições. 
Os dados obtidos segundo estes dois processos foram avaliados em termos de coeficiente de variação. No estudo de precisão e exatidão do método seguiram-se as recomendações e $200 \mathrm{mg}$ de soro de sangue foi utilizado. 
5 - RESULTADOS E DISCUSSÃO

5.1. Metodologia de Detecção de ${ }^{75} \mathrm{se}$

5.1.1. Espectro de Raios Gama de ${ }^{75}$ se

A Figura 2 mostra o espectro de raios gama de ${ }^{75}$ se obtido, de acordo com o procedimento descrito em 4.2.2.1. vários picos de emissão da radiação gama foram obtidos, desde 0,066 ate $0,401 \mathrm{MeV}$, semelhantes ao levantamento espectral efetuado por IEDERER et alii (1967).

Face a estes resultados foram previstas duas maneiras para se contar a atividade de ${ }^{75}$ se nas amostras: a) con tagem no maior fotopico apenas, entre 3,5 e 5,0 volts; b) conta gem integral entre 0,5 e 5,0 volts. No entanto, procurou-se de limitar a região do espectro que fosse mais adequada, tivesse a maior relação sinal/ruído e menor coeficiente de variação para a taxa de contagem liquida da amostra. A mesma foi obtida através de testes preliminares e regulagens no ganho do amplificador do espectrômetro gama. Deve-se salientar que o sinal significa a taxa de contagem liquida e o ruído a taxa de contagem da radiação de fundo. 
KRUG (1975) salienta que a vantagem de se contar na posição integral está no fato de que muitas vezes há flutua-. ção no espectro e uma pequena variação na posição do fotopico poderia influir significativamente nos resultados obtidos. tretanto, convém observar que, quando se trabalha com uma solução padrão de ${ }^{75}$ se de baixa atividade como referência, podem ser feitas as contagens da atividade no maior fotopico e fazer as correções com base na mesma.

No presente estudo optou-se pelas contagens no maior fotopico, entre 3,5 e 5,0 volts, tendo como referência uma solução padrão de ${ }^{75}$ se de concentração variando de 0,05 a $1,00 \mu \mathrm{g} / \mathrm{ml}$ de se e atividade de 2,5 a $50 \mathrm{nCi} / \mathrm{ml}$, respectivamente.

Convém ressaltar que ao maior fotopico está associado o pico-soma, referente aos raios gamas de 0,121 +0,280 Mev. 
45

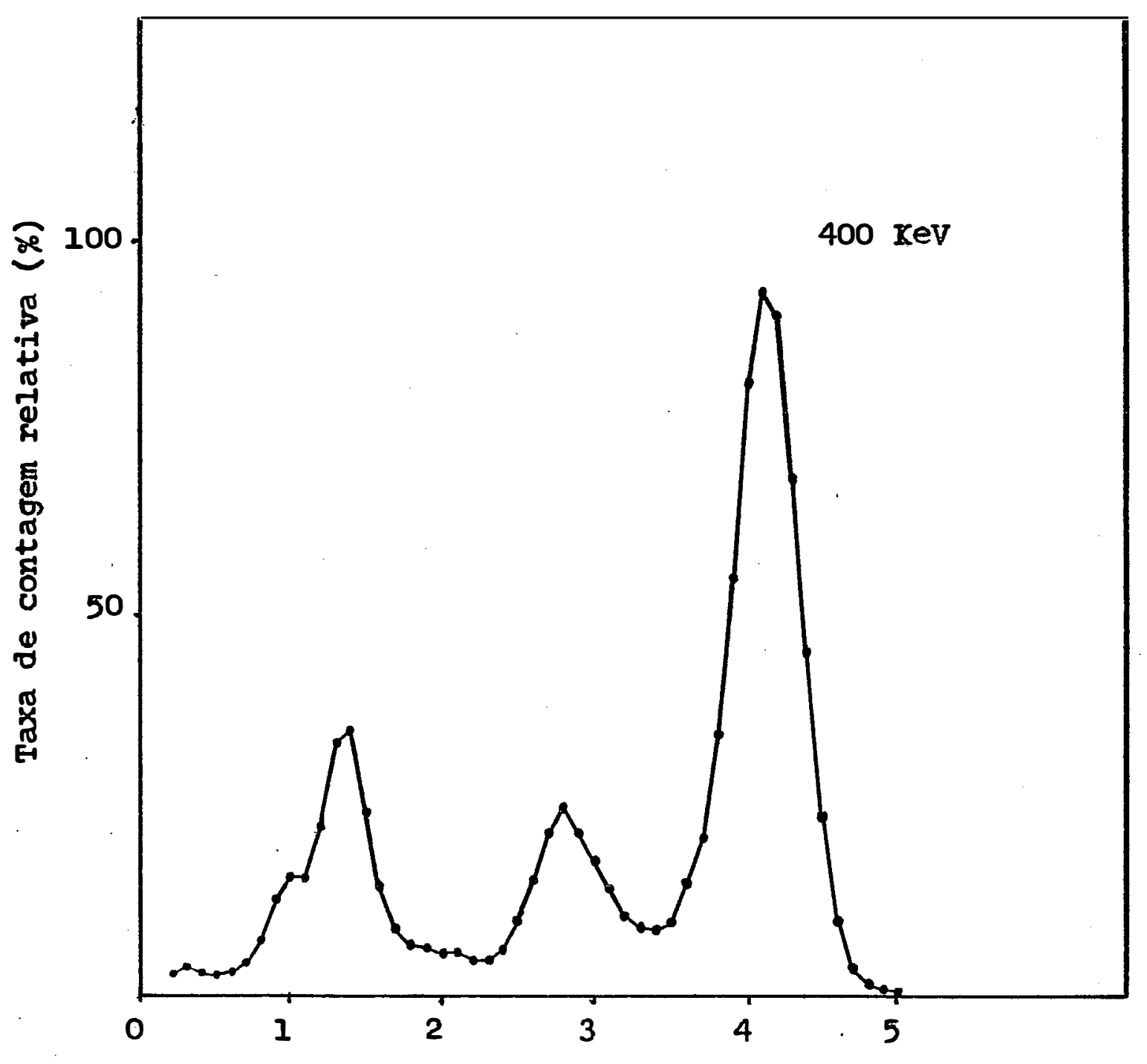

Voltagem de base (v)

FIGURA 2. Espectro de pulsos devido aos raios gama do ${ }^{75}$ Se ( I V $=100 \mathrm{KeV}$ ) 
5.1.2. Efeito da Geometria das Amostras na Detecção de ${ }^{75} \mathrm{se}$

De acordo com o procedimento descrito em 4.2.1.2. foram obtidos os resultados mostrados na Figura 3. No eixo das ordenadas, a taxa de contagem liquida foi transformada em taxa de contagem relativa (\%), em relação à máxima taxa de contagem liquida observada.

Verificou-se (Figura 3) que quando se correlacionam atividades de ${ }^{75} \mathrm{Se}$ ent volumes diferentes ( 1 e $10 \mathrm{ml}$, por exemplo) foram detectadas diferenças entre as taxas de conta gens (cerca de $15 \%$ para o exemplo citado).

os experimentos posteriores foram corrigidos em função dos resultados obtidos na Figura 3, para minimizar o efeito da geometria das amostras e para normalizar os resultados. 




FIGURA 3. Efeito da geometria das amostras na detecção de ${ }^{75} \mathrm{se}$ de $10 \mathrm{nCi} / \mathrm{ml}$. 
5.2. Decomposição de Amostras

5.2.1. Via umida com Ácidos Nitrico e Perclórico

De acordo com o procedimento em 4.2.2.1. foram obtịdos os resultados mostrados nas Figuras 4 e 5 .

Verificou-se na Figura 4 que os resultados obtidos com material vegetal foram satisfatórios e concordaram com os obtidos por OLSON (1969, 1973). Testes preliminares revelaram perdas por volatilização de selênio ao redor de $4 \%$, concordando com os trabalhos de ImNAT (1974b) e WATKINSON (1966).

A recuperação média de selênio por este processo de digestão foi de $104 \%$ e os resultados estão contidos na Tabela 5. Os valores representam a média de duas repetições.

TABELA 5. Recuperação de Selênio em Material Vegetal na Digestão Nitrico-perclórica.

Tratamento

Quantidade de selênio $(\mu g)$ Recuperação $(\%) *$ Adicionada Determinada

\begin{tabular}{lrrr}
\hline 1 & 0,000 & 0,042 & - \\
2 & 0,050 & 0,100 & 108,7 \\
3 & 0,100 & 0,165 & 116,2 \\
4 & 0,200 & 0,235 & 97,1 \\
5 & 0,300 & 0,319 & 93,3 \\
\hline
\end{tabular}

* Recuperação = Quantidade de Se determinada/ $(0,042 \mu \mathrm{g}+$ Quantí dade Adicionada).

Os resultados da Figura 5, obtidos da digestão de $1,0 \mathrm{ml}$ de soro de sangue, também foram satisfatórios para o método proposto. A recuperação média de selênio foi de $95 \%$ e os resultados estão 


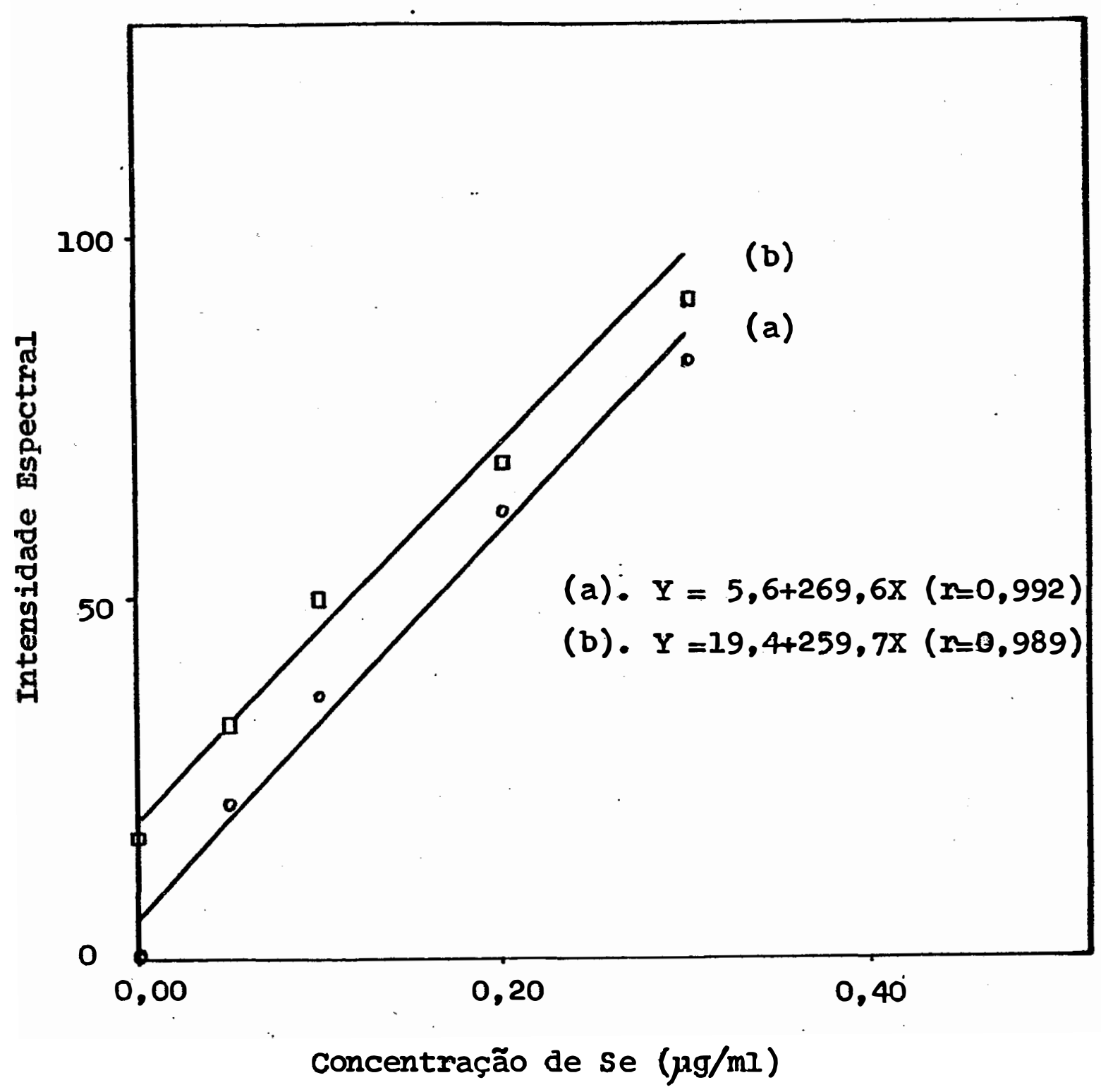

FIGURA 4. Recuperação de selênio em material vegetal na digestão nitrico-perclórica: (a) sem amostra e (B) com amostra. 


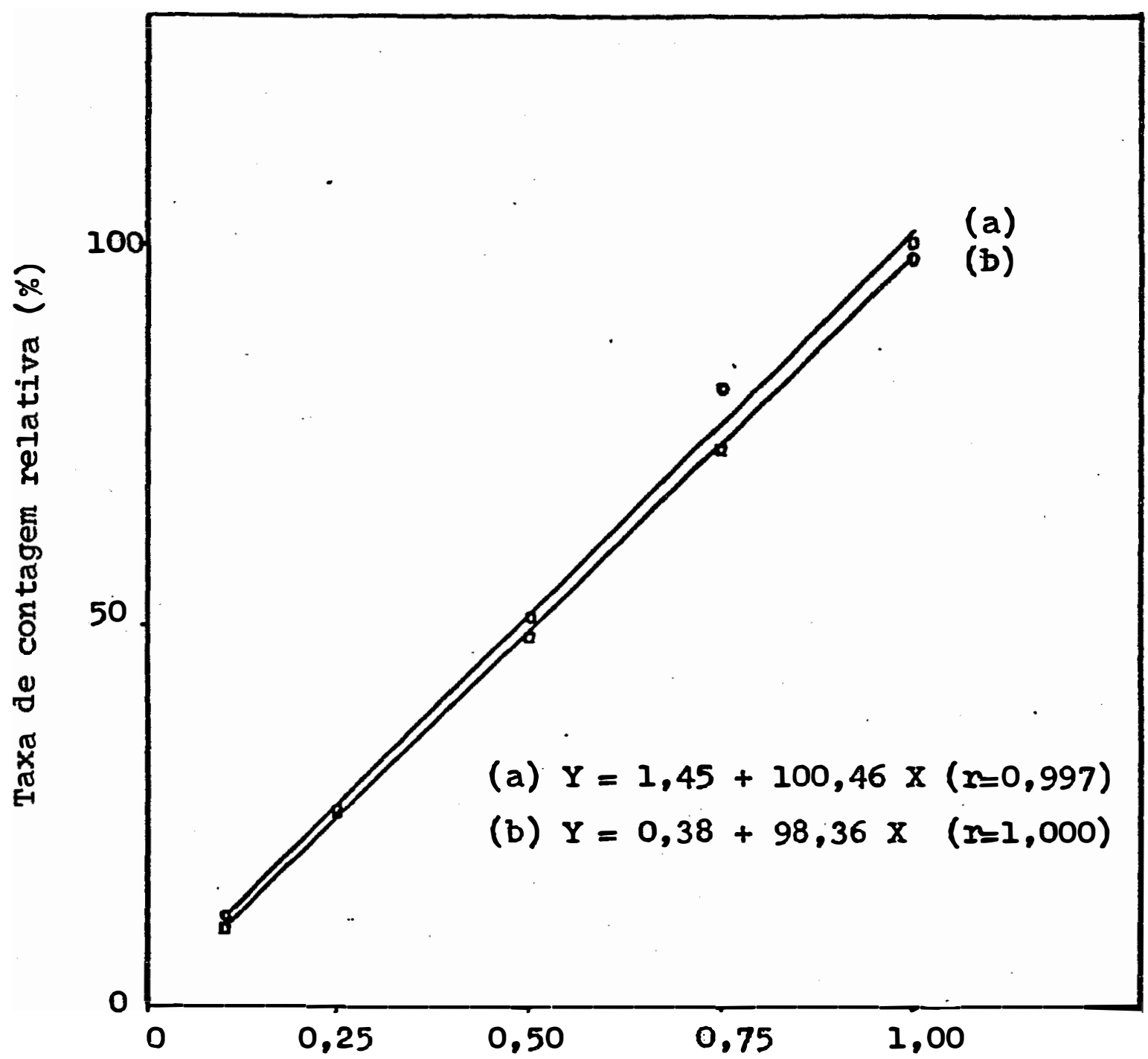

Concentração de Selênio $(\mu \mathrm{g} / \mathrm{ml})$

FIGURA 5. Recuperação de selênio em soro de sangue em digestão nitrico-perclórica (a) sen amostra e (b) com amostra. 
na Tabela 6. Os valores representam a média de duas repetiçôes. TABELA 6. Recuperação de selệnio em soro de sangue na digestão nitrico-perclorica.

Tratamento

Quantidade de selênio ( $\mu g)$ Recuperação (\%)* Adicionada Determinada

\begin{tabular}{llll}
\hline 1 & 0,100 & 0,094 & 94,0 \\
2 & 0,250 & 0,239 & 95,6 \\
3 & 0,500 & 0,465 & 93,0 \\
4 & 0,750 & 0,714 & 95,2 \\
5 & 1,000 & 0,981 & 98,1 \\
\hline
\end{tabular}

* Recuperação = Quantidade Se determinada/Quantidade se adicionada.

Em vista do excelente resultado obtido com estes dois substratos, este processo de digestão nitrico-perclórica foi adotado.

5.2.2. Via Omida com Acidos Sulfbrico e Percl6rico

De acordo com o procedimento descrito em 4.2.2.2. foram obtidos os resultados mostrados nas Figuras 6 e 7 .

Na Figura 6, a curva referente à amostra apresentou uma taxa de contagem relativa superior à curva sem amostra, em todos os níveis de selênio utilizados. Uma possivel explicação poderia ser a presença de alguma substância no soro de sangue que converteu o selênio (VI) para selênio (IV), que é a for ma que reage com $O$ DAN. Era de se esperar um resultado semelhan te ao obtido na Figura 4. 
A Figura 7 mostra os resultados obtidos com a digestão de ração animal. Observou-se que, com a digestão de apenas 0,10 gramas de ração aumentou em cerca de $65 \%$ a percentagem da taxa de contagem relativa $e$, os aumentos subsequentes.

na quantidade de ração ainda aumentaram a taxa de contagem relativa porem, foram menores. Foi diffcil de ser interpretado este resultado pois, foi adicionada uma concentração e atividade definida de ${ }^{75} \mathrm{se}$ em todas as quantidades de ração. Para explicar - ocorrido, o mesmo raciocínio anterior foi proposto, talvez alguma substância da ração estivesse favorecendo a transformação de selênio (VI) para selênio (IV).

Em ambos os testes, não pudemos comprovar esta hifotese experimentalmente. Sugere-se no entanto, novos estudos a respeito deste processo de digestão.

Devido aos resultados obtidos, este processo de digestão não foi adotado.

5.2.3. Via seca com frasco de combustão de schbniger

seguindo o procedimento descrito em 4.2.2.3. foram obtidos os resultados mostrados na Tabela 7 . Os valores representam a média de duas repetições.

A atividade esperada foi calculada com base na so lução padrão de ${ }^{75}$ se adicionada aos balões volumetricos de 25 e $50 \mathrm{ml}$. A atividade observada foi calculada com base na atividade da solução absorvedora após a digestão da amostra.

os baixos percentuais de recuperação de selênio , 4 e $8 \%$ para 25 e $50 \mathrm{ml}$ de solução absorvedora, respectivamente, foram devidos à maior retenção de selênio nas cinzas e foi com- 




Quantidade de selênịo ( $\mu g$ )

FIGURA 6. Recuperação de selênio em soro de sangue em digestão sulfo-perclórica: (a) sem amostra e (b) com amostra. 
TABELA 7. Recuperação de ${ }^{75}$ Se em silagem de milho através do frasco de combustão de schoniger

\begin{tabular}{|c|c|c|c|}
\hline $\begin{array}{l}\text { Solução } \\
\text { absorvedora(ml) }\end{array}$ & $\begin{array}{l}\text { Taxa de contagem } \\
\text { esperada }(\mathrm{cpm}) *\end{array}$ & $\begin{array}{c}\text { Taxa de contagem } \\
\text { observada ( } \mathrm{cpm})\end{array}$ & 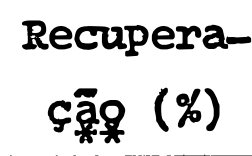 \\
\hline 25 & 9096 & 354 & 3,89 \\
\hline 50 & 4098 & 323 & 7,88 \\
\hline
\end{tabular}

* $\quad \mathrm{cpm}=$ contagens por minuto.

** recuperação $=$ cpm observada/cpm esperada.

provado quando se contou sua atividade e encontrou $105.000 \mathrm{cpm}$ (quase a totalidade da atividade da solução inicialmente adicionada).

Uma possível explicação desta elevada retenção de selênio pelas cinzas poderia ser a presença do bacto-agar , que pode agregar as partículas de silagem na confecção dos peletes que dificultou a liberação do selênio da silagem para a solução absorvedora.

Face aos resultados obtidos e a não concordância com os trabalhos de EUTENMANN e IISK (1961), sugere-se, para estudos futuros: não utilizar o bacto-agar para confeccionar peletes, incorporar as cinzas na solução absorvedora, utilizar diferentes volumes de solução absorvedora e outras soluções absorvedoras.

Este processo de digestão tambén não foi adotado. 
5.3. Metodologia de Determinação

\subsubsection{Concentração do 2,3-diaminonaftaleno (DAN)}

veis de ${ }^{75}$ se estão na Figura 8.

Uma variação de 10 vezes na concentração de DAN, de $2 \times 10^{-3}$ a $2 \times 10^{-2} \mathrm{M}$, provocou uma variação percentual média nas taxas de contagens relativas em torno de $30 \%$, em todos os niveis de selênio utilizados, evidenciando o efeito da concentração de DAN na reação de complexação entre o selênio e o DAN.

As concentrações de selênio nos solos e plantas geralmente estão ao redor de 0,20 ppm e, para esta concentração, cerca de $2 \times 10^{-2} \mathrm{M}$ de DAN foi a indicada (Figura 8).

Neste experimento foi utilizado somente $1,0 \mathrm{ml}$ de DAN para as diferentes concentrações, porém, no método proposto foi escolnido $5,0 \mathrm{ml}$ de $\mathrm{DAN} 4 \times 10^{-3} \mathrm{M}$, para aumentar 0 volume da fase aquosa.

Em todos os experimentos subsequentes foram utilizados $5,0 \mathrm{ml}$ de DAN $4 \times 10^{-3} \mathrm{M}$, concordando com as concentrações utilizadas pelos demais autores (vide 4.2.3.1.).

5.3.2. Efeito do tempo e temperatura na reação

Estudoumse o efeito do tempo e temperatura na formação do complexo se-DAN com DAN $4 \times 10^{-3}$ M. os resultados estão na Figura 9.

As curvas da Figura 9 mostraram que para todas as temperaturas estudadas, a reação entre o DAN e o selênio au mentaram com o tempo, atingiram um máximo de complexação aos 


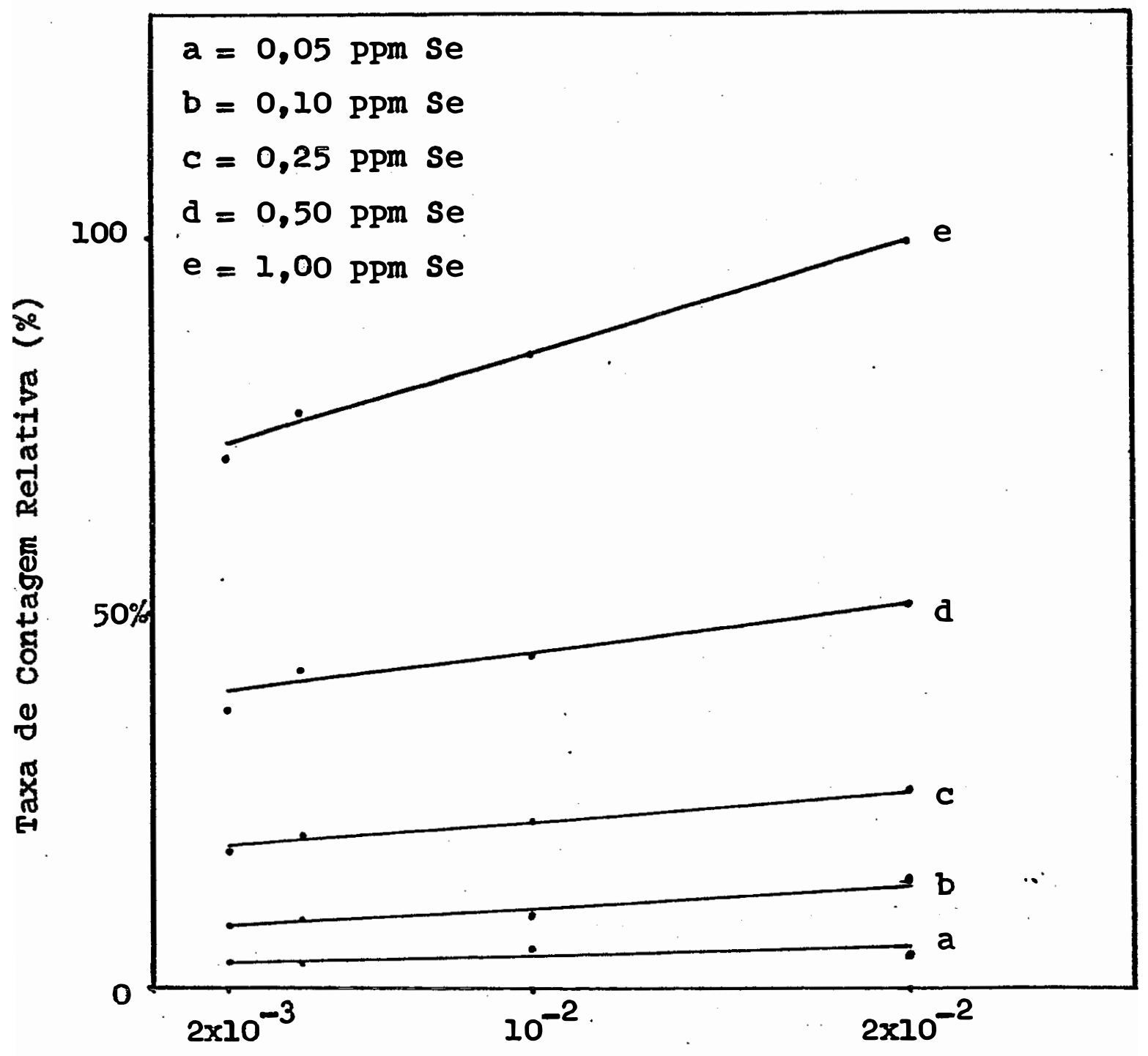

Concentração de DAN (Molaridade)

FIGURA 8. Influência da concentração de DAN na extração de selênio ( 1 ml de DAN) 
60 minutos, decresceram até mais ou menos 180 minutos e depois se estabilizaram até 240 minutos. Também foi verificado que as maiores complexações ocorreram nas temperaturas mais elevadas, concordando com os trabalhos de LOTT et alii, (1963).

Com estes resultados ficou bem claro que realmen te o tempo e a temperatura têm grande influência na complexação do selênio pelo DAN.

Foi escolhida a temperatura de 700C e o tempo de 60 minutos de reação para o método proposto, porque foi observado que nas temperaturas mais elevadas ocorreram pequenas per das por volatilização da fase aquosa e isto poderia causar alguma variação nos resultados finais e também, estas perdas não foram uniformes em todos os tubos de digestão. Convém observar que tais perdas podem ser contornadas colocando-se pequenos fu nis na boca dos tubos de digestão para promover o refluxo.

5.3.3. Influência do solvente orgânico

A Tabela 8 mostra os resultados da extração do complexo Se-DAN por diferentes solventes orgânicos.

A solução padrão de ${ }^{75}$ se utilizada apresentou uma taxa de contagem liquida de $12.535 \mathrm{cpm}$, sendo a contagem relativa à radiação de fundo, de $319 \mathrm{cpm}$. 


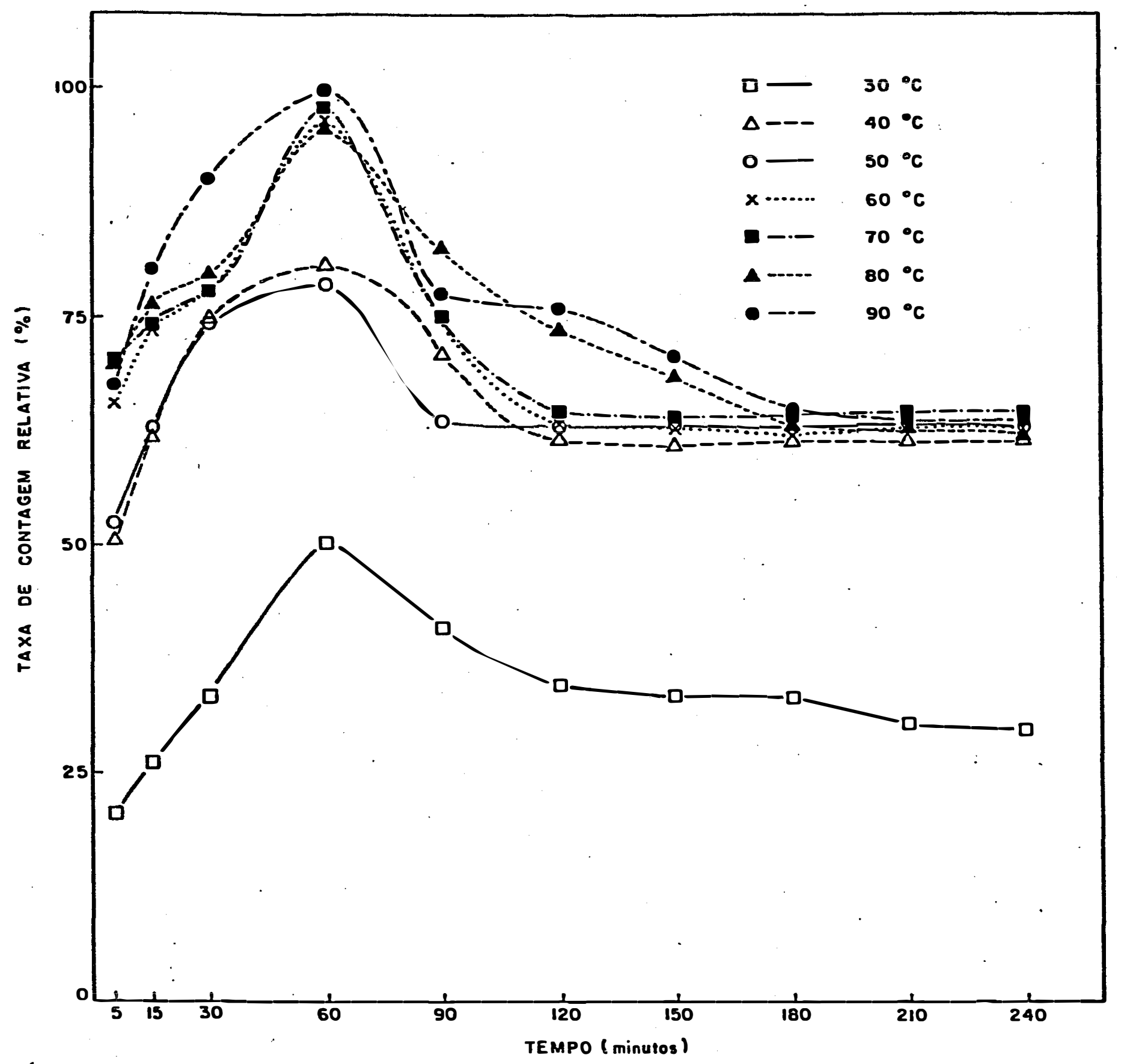

FIGURA 9. Efeito do tempo e da temperatura na formação do complexo Se-DAN. 
TABELA 8. Estuḍo de diferentes solventes orgânicos como extratores do complexo Se-DAN.

\begin{tabular}{lcccc}
\hline Solvente orgânico & $\begin{array}{l}\text { Média } \\
(\mathrm{cpm})\end{array}$ & $\begin{array}{c}\text { Desvio } \\
\text { padrão } \\
(\mathrm{cpm})\end{array}$ & $\begin{array}{c}\text { Extração } \\
(\%)\end{array}$ & $\begin{array}{c}\text { Extração } \\
\text { relativa } \\
(\%)\end{array}$ \\
\hline Ciclohexano & 7.749 & 66 & 61,8 & 100,0 \\
Benzeno & 4.898 & 57 & 39,1 & 63,2 \\
Metil-isobutil-cetona & 4.516 & 4 & 36,0 & 58,3 \\
Clorofórmio & 4.327 & 117 & 34,5 & 55,8 \\
Alcool isoamilico & 4.183 & 100 & 33,4 & 54,0 \\
Acetato de etila & 3.169 & 136 & 25,3 & 40,9 \\
Tetracloreto de & & & & 37,7 \\
Carbono & 2.920 & 48 & 23,3 & 22,0 \\
Hexano & 1.707 & 42 & 13,6 & \\
\hline
\end{tabular}

Pelos resultados da Tabela 8 o ciclohexano foi o melhor extrator do complexo Se-DAN segundo a metodologia utili zada; apresentou uma elevada percentagem de extração cerca de $62 \%$, enquanto que os demais foram 37 a $78 \%$ inferiores ao ciclo hexano.

CUKOR et alii (1964) testaram 5 tipos de solventes orgânicos na extração do complexo se-DAN e encontraram os seguintes resultados em percentuais de extração: ciclohexano 23,8; tolueno - 22,2; cloreto de etileno - 20,0; clorofórmio 20,0 e tetracloreto de carbono - 19,4. Embora o procedimento de determinação destes autores seja diferente do método propos to, seus resultados também mostraram que o ciclohexano foi 0 melhor agente extrator. 0 baixo percentual de extração obtido 
pelos autores possivelmente são devidos às diferenças de método.

En face dos resultados obtidos, o ciclohexano foi escolhido como agente extrator do método proposto. Convém salientar ainda, que o ciclohexano é encontrado no mercado com elevado grau de pureza, é pouco solúvel em água (Tabela 2), o seu preço é razoavelmente baixo quando comparado com os demais solventes e, alia boas caracteristicas para se trabalhar na extração por solventes orgânicos.

5.3.4. Efeito da razão fase aquosa/fase orgânica

o efeito da razão fase aquosa/fase orgânica pode ser visto nas Figuras 10 e 11. A solução padrão de ${ }^{75}$ se foi a mesma nos dois experimentos e apresentou uma taxa de contagem líquida de $77.844 \mathrm{cpm}$ e a aliquota de $5 \mathrm{ml}$ de fase aquosa $18.013 \mathrm{cpm}$.

0 volume da fase aquosa foi constante nos dois experimentos, cerca de $21,5 \mathrm{ml}$ e da fase orgânica foi variável até 6 e até $10 \mathrm{ml}$, respectivamente para as Figuras $10 \mathrm{e} 11$.

Observou-se na Figura 10 que a extração de selênio da fase aquosa até o limite de $6 \mathrm{ml}$ de fase orgânica, inde pende da razão fase aquosa/fase orgânica. Praticamente o mesmo resultado foi observado na Figura 1l, porém, acima de $6 \mathrm{ml}$ de fase orgânica foi notada uma leve influência da razão fase aquo sa/fase orgânica na extração do Se-DAN.

Estudos desta natureza, para a extração de selênio não foram constatados na literatura até o presente momento. Em face dos resultados obtidos, procurou-se padronizar a razão fase aquosa/fase orgânica para os demais ex 


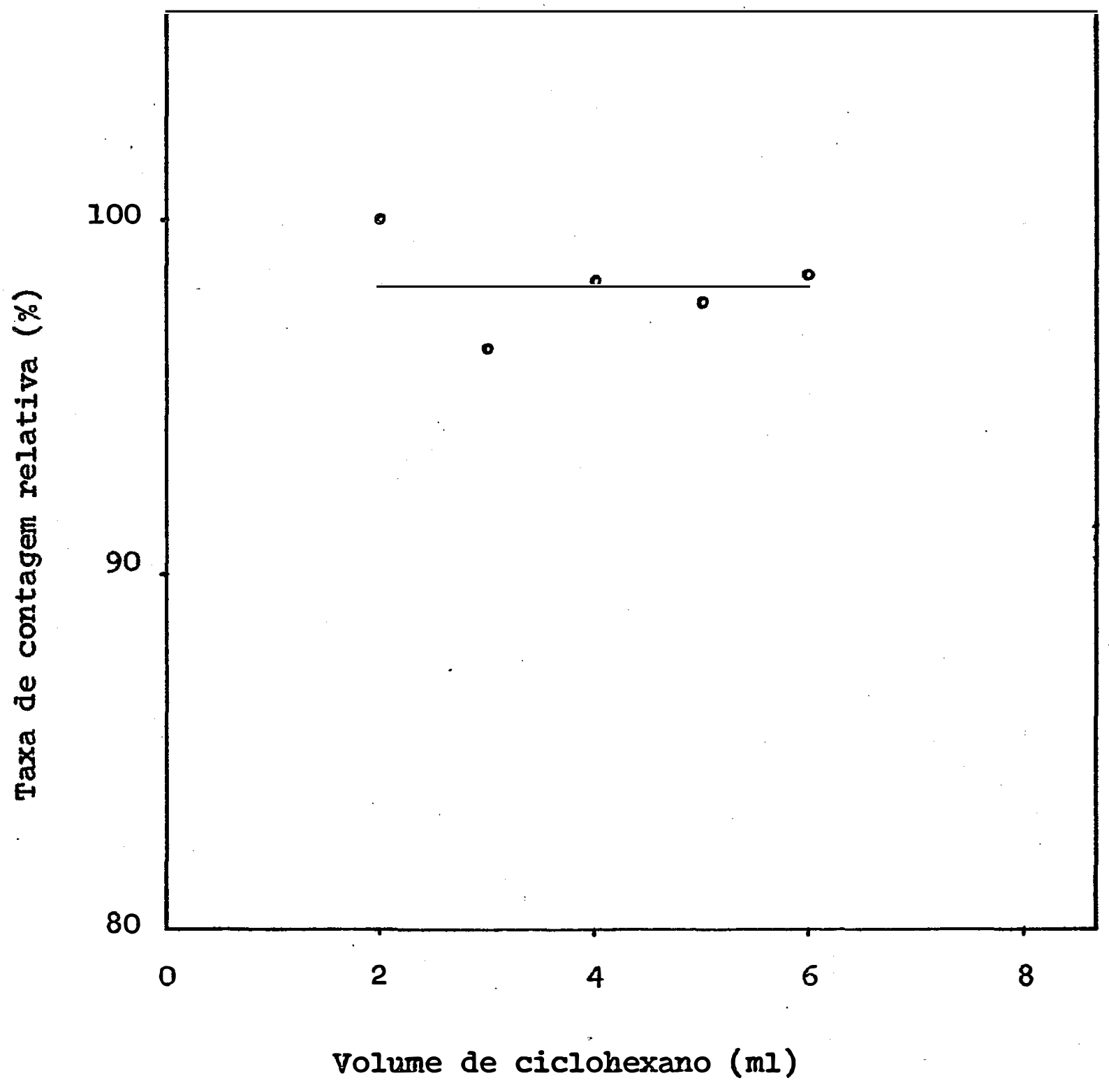

FIGURA 10. Efeito da razão fase aquosa/fase orgânica com fase aquosa constante ao redor de $21,5 \mathrm{ml} e$ fase orgânica variando de 2 a $6 \mathrm{ml}$. 


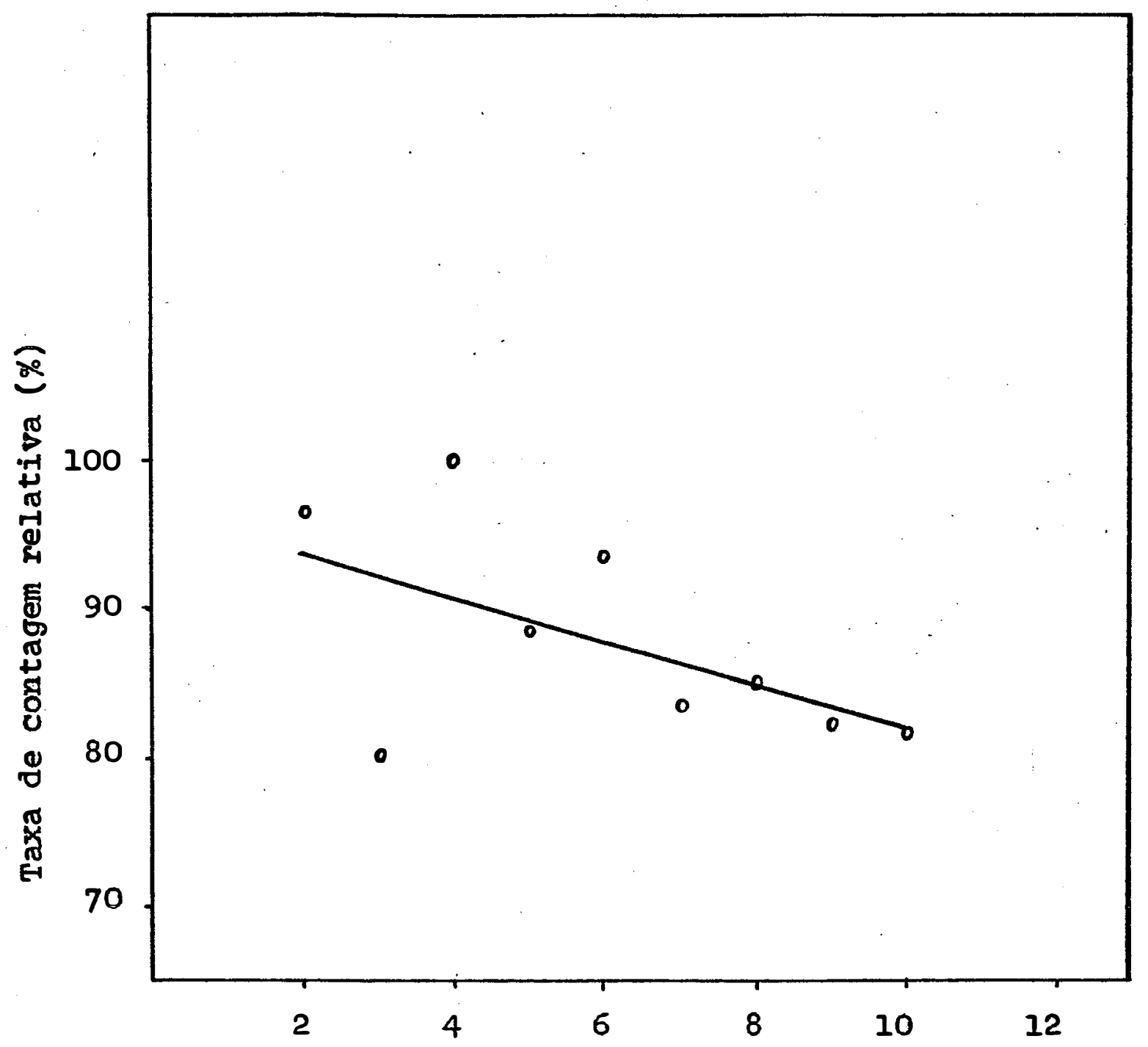

Volume de ciclohexano (ml)

FIGURA 11. Efeito da razão fase aquosa/fase orgânica com fase aquosa constante ao redor de $21.5 \mathrm{ml}$ e fase orgânica variando de 2 a $10 \mathrm{ml}$. 
perimentos, principalmente no tocante ao volume de solvente or gânico a fim de não alterar o efeito da geometria das amostras na deteç̧ão de ${ }^{75} \mathrm{se}$. Devido a isto, optou-se por um volume de $5 \mathrm{ml}$ de ciclohexano, concordando com o estudo da geometria das amostras descrito en 5.1.2.

5.3.5. Cinética de extração

o efeito do tempo de agitação da solução aquosa com a orgânica foi verificado e os resultados são mostrados na Figura 12. A solução padrão de ${ }^{75}$ se apresentou uma taxa de con tagens liquida de $12.411 \mathrm{cpm}$ e sendo a contagem relativa à radiação de fundo de $326 \mathrm{cpm}$.

De acordo com a Tabela 4, os autores que trabalharam com ciclohexano recomendavam que se agitasse as duas fa ses por 1 minuto (WATKINSON, 1966) ou 5 minutos (COKOR et alii, 1964; HOFFMAN et alii, 1968). No entanto, os resultados obtidos (Figura 12), mostraram que a transferência do complexo seDAN da fase aquosa para a fase orgânica não depende do tempo de agitação e o equilíbrio é alcançado após as fases terem sido intimamente agitadas por 15 segundos, sem haver necessidade de se agitar além deste tempo como recomendavam outros autores.

o tempo de 15 segundos de agitação foi escolhido e adotado no método proposto.

5.3.6. NGmero de extrações

o efeito do número de extrações do complexo seDAN foi investigado e os resultados estão nas Tabelas 9 e 10.

Em ambos os experimentos a percentagem da la e 2a extração foi calculada com base na taxa de contagem líquida 


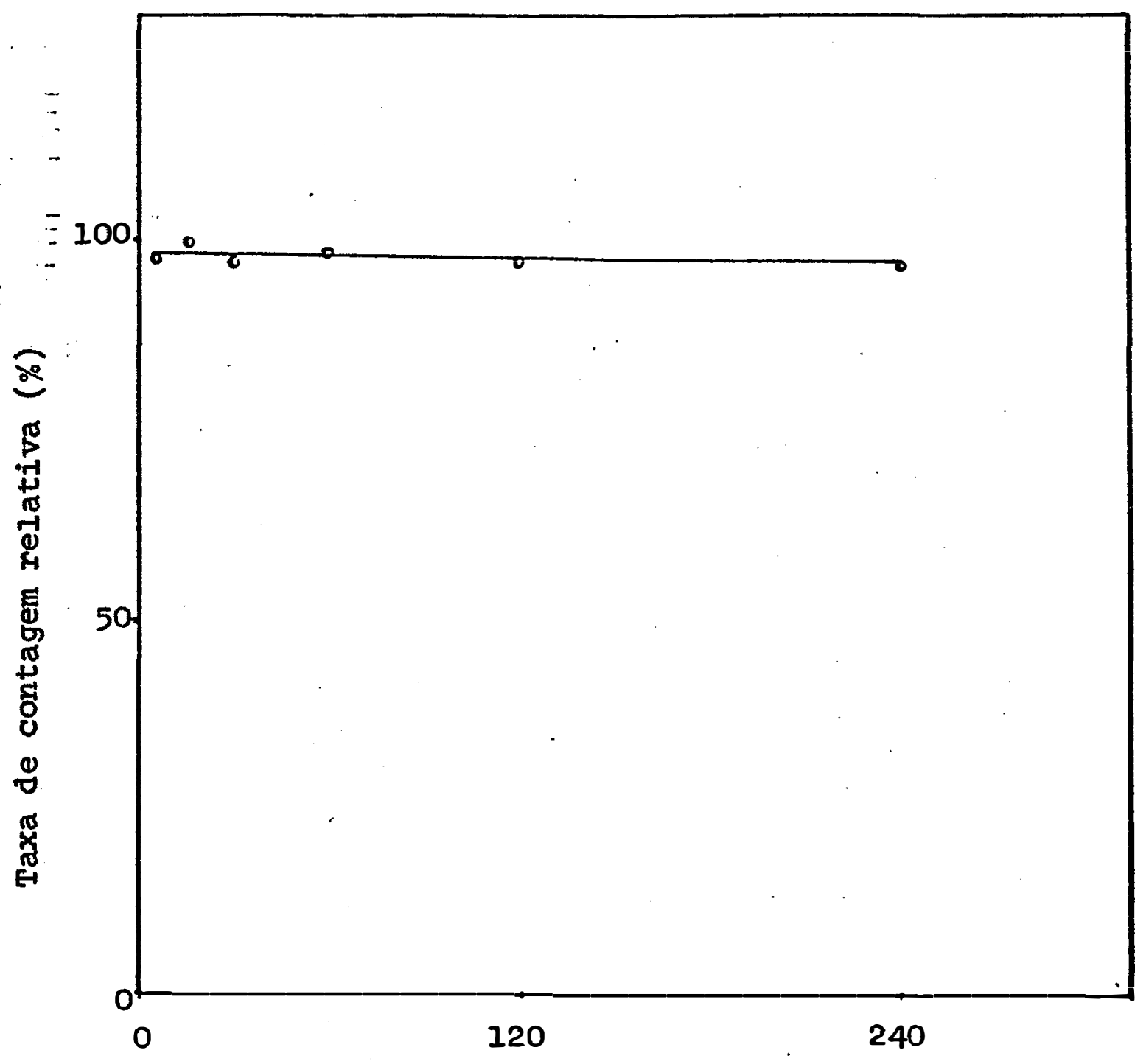

Tempo (segundos)

FIGURA 12. Efeito do tempo de agitação das duas fases para transferência do complexo se-DAN para a fase orgânica de ciclohexano. 
(CL) total e, a percentagem de extração total foi calculada com base na soma da 13 com a 2 a extração.

Nos resultados da Tabela 9 foi utilizada uma solução padrão de ${ }^{75}$ se com $73.333 \mathrm{cpm}$ e na Tabela 10 a taxa de contagem liquida foi de $12.340 \mathrm{cpm}$.

TABELA 9. Efeito do número de extrações do complexo se-DAN com ciclohexano

\section{1a Extração 2a Extração}

C.I. Média (cpm)

Desvio padrão (cpm)

Extração (\%)
50.075

105

68,3
3848

180

5,2
Extração Total (\%)

1 Extração/Extração Total
73,5

92,9

Vários solventes orgânicos tambem foram testados quanto ao número de extrações para facilitar outros pesquisado res que, porventura se utilizarão do método proposto e não dis ponham do ciclohexano e também, para verificar. se uma $2 \underline{a}$ extra ção aumentaria a percentagem de extração total para estes solventes. Os resultados estão contidos na Tabela 10. 
TABELA 10. Efeito do número de extrações do complexo se-DAN com diferentes solventes.

Solvente Orgânico la Extr. 2 a Extr. Extr. 1a Extr./ Extr. Rel. Extr. Total Rel. Extr.Tot.

\begin{tabular}{|c|c|c|c|c|c|c|}
\hline \multirow[b]{2}{*}{ Ciclohexano } & \multicolumn{5}{|c|}{$(\%)$} & \multirow[b]{2}{*}{93,0} \\
\hline & 61,8 & 100,0 & 4,7 & 66,5 & 100,0 & \\
\hline Benzeno & 39,1 & 63,3 & 5,0 & 44,1 & 66,4 & 88,7 \\
\hline \multicolumn{7}{|l|}{ Metil-isobutil- } \\
\hline cetona & 36,0 & 58,3 & 3,2 & 39,2 & 59,0 & 91,9 \\
\hline Clorofórmio & 34,5 & 55,8 & 7,7 & 42,2 & 63,8 & 81,7 \\
\hline Alcool isoamilico & 33,4 & 54,0 & 5,0 & 38,4 & 57,8 & 86,9 \\
\hline $\begin{array}{l}\text { Acetato de etila } \\
\text { Tetracloreto de }\end{array}$ & 25,3 & 40,9 & 7,8 & 33,1 & 49,7 & 76,5 \\
\hline carbono & 23,3 & 37.7 & 5,0 & 28,3 & 42,6 & 82,2 \\
\hline
\end{tabular}

Analisando as Tabelas 9 e 10 verificou-se que uma única extração com o ciclohexano foi suficiente para extrair cerca de $93 \%$ do complexo se-DAN que seria extraido através de duas extrações. Observou-se na Tabela 10 que também uma so extração com os demais solventes já foi suficiente para extrair a maior parte do complexo Se-DAN possivel de ser extraído.

os dados obtidos nas Tabelas 9 e 10 discordam do trabalho de CuxoR et alii (1964), que recomendavam duas extrações com 10 e $5 \mathrm{ml}$ de ciclohexano, respectivamente, e combinação dos dois extratos. Porém, como foi comentado em 5.2.3.6., tal procedimento acarreta no aumento de volume da fase orgâni- 
ca e consequente diminuição na sensibilidade. Portanto, em face dos resultados obtidos foi recomendada uma lnica extração com 5 ml de ciclohexano.

\subsubsection{Precisão e exatidão do método}

Na Figura 13 foi encontrada uma correlação linear bem próxima de 1. Com base na equação da curva foi calculado o teor médio de selênio no soro de sangue.

os resultados da precisão do método, segundo a curva padrão estão contidos na Tabela ll e Figura 13.

TABELA 11. Resultados do teor de selênio na amostra referência de soro de sangue pela curva padrão.

Soro de sangue (200 $\mathrm{mg})$

Teor médio de se (PPm)

Coeficiente de variação $(\%)$

$$
\begin{gathered}
0,55 \pm 0,05 \\
9,1
\end{gathered}
$$

Pelos resultados obtidos (Tabela 11), o método proposto apresentou boa precisão e pode ser comprovado quando se confronta o coeficiente de variação encontrado com o reco mendado pela Agência, 9 e 15\%, respectivamente.

os resultados da precisão do método, segundo a técnica do padrão interno estão contidos na Tabela 12 e Figura 14.

Os dados da Tabela 12 vêm confirmar a boa precisão jâ alcançada com o método. Com a técnica do padrão intemo foi obtido um coeficiente de variação médio de $8,7 \%$ e uma re- 




Concentração de selênio $(\mu \mathrm{g} / \mathrm{ml})$

FIGURA 13. Curva padrão do selênio em solução aquosa. 
TABELA 12. Precisão da determinação e recuperação de selênio na referência de soro de sangue.

\begin{tabular}{cccc}
\hline $\begin{array}{c}\text { Selênio } \\
\text { adicionado } \\
\text { (PPm) }\end{array}$ & $\begin{array}{c}\text { Selênio } \\
\text { determinado } \\
(\mathrm{PPm})\end{array}$ & $\begin{array}{c}\text { Coeficiente } \\
\text { de variação } \\
(\%)\end{array}$ & $\begin{array}{c}\text { Recuperação * } \\
(\%)\end{array}$ \\
\hline 0 & $0,009 \pm 0,002$ & 22,22 & - \\
0,10 & $0,094 \pm 0,005$ & 5,32 & 86,2 \\
0,20 & $0,183 \pm 0,006$ & 3,28 & 87,6 \\
0,30 & $0,313 \pm 0,012$ & 3,83 & 101,3
\end{tabular}

* Recuperação $=\mathrm{pPm}$ se determinado $/(0,009+\mathrm{pPm}$ se adicionado $)$

cuperação média de 91,7\%. o método proposto também apresentou boa precisão pela técnica do padrão intemo.

os resultados da exatidão do método, segundo o procedimento descrito em 4.2.3.7. podem ser observados na Tabela 11 (pela curva padrão em solução aquosa) e Figura 14 ( pela técnica do padrão interno).

Na Tabela 11, o teor médio de selênio encontrado foi de $0,55 \pm 0,05 \mathrm{ppm}$, enquanto que o valor recomendado era de $0,59 \pm 0,09 \mathrm{ppm}$. Portanto, o valor encontrado está próximo do valor recomendado e o método proposto pode ser considerado exato.

Na Figura 14, o prolongamento da reta até encontrar o eixo $\mathrm{X}$ resultou (em valores absolutos), no valor $0,13 \mu \mathrm{g}$ se porém, este teor está contido em $200 \mathrm{mg}$ de soro de sangue e, em $1 \mathrm{~g}$ corresponde a 0,65 ppm de se. Este valor também está pró ximo do valor recomendado e mais uma vez o método comprovou que 


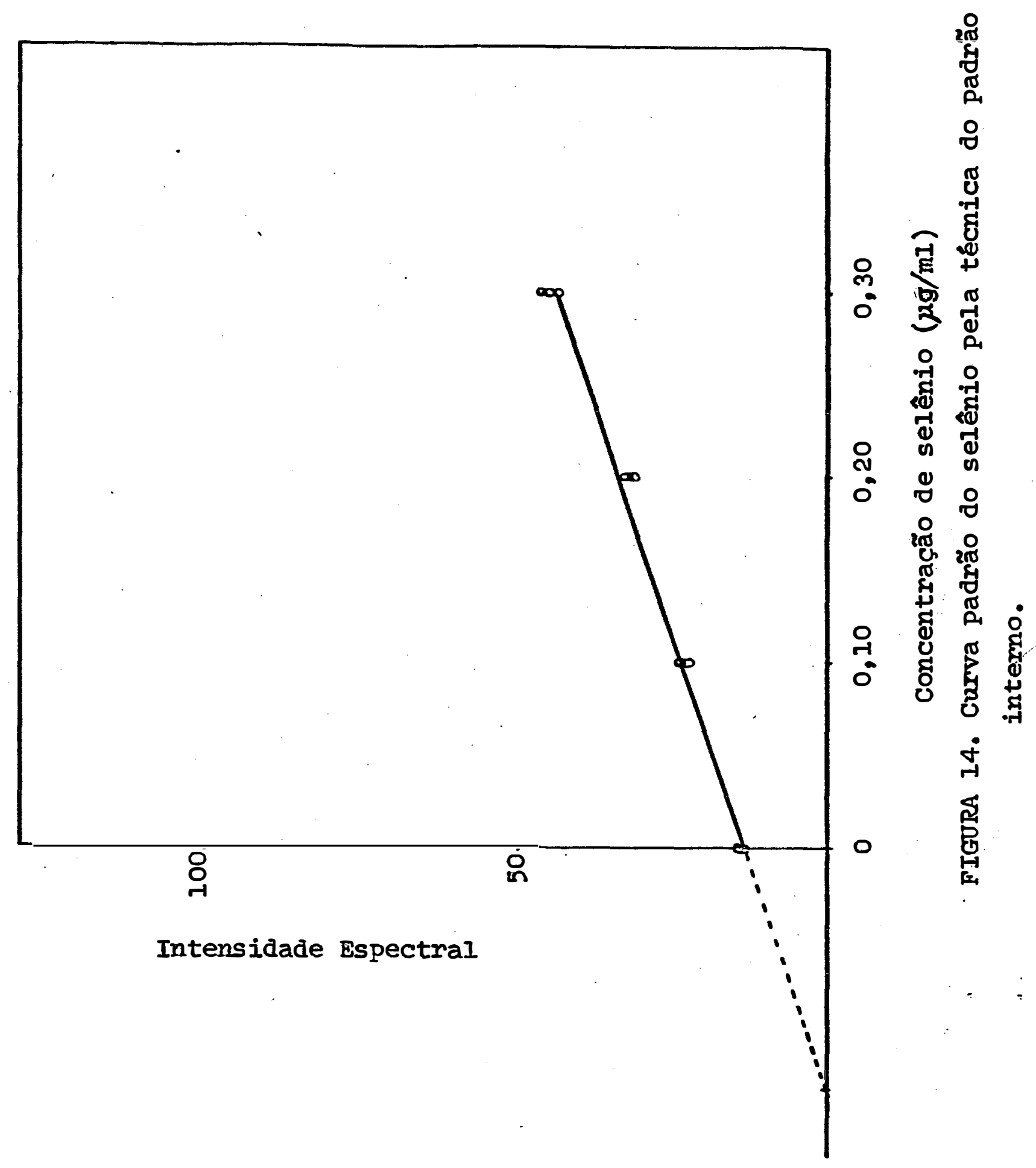


foi exato.

Portanto, para o material analisado, o método proposto foi preciso e exato. 
6 - CONCLUSŐES

Nas condições em que o método foi desenvolvido e de acordo com os resultados obtidos, as seguintes conclusões po dem ser feitas:

a - o método de determinação de selênio por - fluorimetria pode ser utilizado para a determinação de selênio em extratos de plantas e soro de sangue.

b - o uso de material radioativo na otimização de algumas etapas analíticas foi de indiscutivel valor e pode ser utiliza da como uma excelente ferramenta no aprimoramento de métodos analíticos convencionais.

c - a adição de $\mathrm{HCl}(1+9)$ no digerido final e posterior aquecimento a 90oc por 30 minutos foi eficiente em converter o se (VI) para se (IV).

d - em todas as temperaturas estudadas, 30 a 90ㄷ, a máxima com plexação de selênio pelo DAN ocorreu aos 60 minutos e foi máxima a 900C. 
e - o ciclohexano foi um excelente extrator do complexo Se-DAN, segundo o método proposto.

f - a transferência do complexo Se-DAN da fase aquosa para a fase orgânica não depende do tempo de agitação das duas fases.

g - uma única extração com $5 \mathrm{ml}$ de ciclohexano foi suficiente para extrair a maior parte do complexo Se-DAN.

h - o método proposto foi preciso e exato, podendo ser utilizado em análises de rotina. 


\section{7 - LITERATURA CITADA}

ALLAWAY, W.H. e E.E. CARY, 1964. Determination of submicrogram amounts of selenium in biological materials, Anal. Chem., Washington, 36:1359-1362。

BALLAUX, C.; R. DANS e H. HOSTE, 1968. Neutron activation analysis of high-purity selenium. Part II: Determination of tellurium. Anal. Chim. Acta, New York, 4l:147-154.

BELCHER, R.; T. KOUIMTZIS e A. TOWNSHEND, 1974. Molecular emission cavity analysis - A new flame analytical technique. Part II: The determination of selenium and tellurium. Anal. Chim. Acta, New York, 68:297-304.

BOWEN, H.J.M., 1966. Trace Elements in Biochemistry. London, Academy Press. 241.P。

CARDOSO, E.G., 1978. Suplementação de selênio e qualidade de sêmen de touros. Piracicaba, ESALQ/USP, 105 P. (Dissertação de Mestrado).

CARY, E.E. e W.H. ALLAWAY, 1969. The stability of different forms of selenium applied to low-selenium soils. Soil sci. 
Soc. Amer. Proc., Madison, Wisconsin, 33:571-574.

CHAKRABARTI, C.I., 1968. The atomic absorption spectroscopy of selenium. Anal. Chim. Acta, New York, 42:379-387.

CHAMBERS, J.C. e B.E. MCCLELLAN, 1976. Enhancement of atomic absorption sensitivity for copper, cadmium, antimony, arsenic and selenium by means of solvent extraction. Anal.Chem., Washington, 48:2061-2066.

CHAN, C.C.Y., 1976. Improvement in the fluorimetric determination of selenium in plants materials with 2,3-diaminonaphthalene. Anal. Chim. Acta, New York. 82:213-215.

CHAU, Y.K. e J.P. RILEY, 1965. The determination of selenium in sea water, silicates and marine organisms. Anal. Chim. Acta. 33: $36-49$.

CHENG, K.I. 1956. Determination of traces of selenium. 3,3' diaminobenzidine as selenium (IV) organic reagent. Anal. Chem. Washington. 28:1738-1742.

CLINTON, O.E., 1977. Determination of selenium in blood and plant material by hydride generation and atomic-absorption spectroscopy. The Analyst, Picadilly, London. 102:187-192. CROSBY, N.T., 1977. Determination of metals in foods - A review The Analyst, Picadilly, London, 102:225-268. CUKOR, P.; J. WALZCYK e P.F. LOTT, 1964. The application of isotopic dilution analysis to the fluorimetric determination of selenium in plant material: Anal. Chim. Acta, New York, 30: 473-482. 
CUMMINS, L॰M.; J.L. MARTIN; G.W॰ MAAG e D.D. MAAG, 1964. rapid method for the determination of selenium in biological material. Anal. Chem., Washington. 36:382-384.

DANS, $R$ e J. HOSTE, 1968. Neutron activation analysis of traces - in electrolytic zinc sulphate solutions. Anal. Chim. Acta, • New York. 41:205-215.

DANZUKA, T. e K. UENO, 1958. Determination of trace amounts of selenium in sulfuric acid. Anal. Chem. Washington. 30:13701371.

DYE, W.B.; E. BRETTHAUER; H.J• SEIM e C. BLINCOE, 1963. Fluorometric determination of selenium in plants and animals with 3,3' - diaminobenzidine. Anal. Chem. Washington. 35: 1687-1693.

EWAN, R.C.; C.A. BAUMANN e A.L. POPE, 1968. Determination of selenium in biological materials. J. Agr. Food Chem. Washington. 16:212-215.

FEIGL, F., 1961. Detection of selenium in organic spot test analysis. Anal. Chim. Acta. New York, 24:501-504.

FIORINO, J•A.; J•W. JONES e S.G. CAPAR, 1976. Sequential determination of arsenic, selenium, antimony and tellurium in foods via rapid hydride evolution and atomic absorption spectrometry. Anal. Chem., Washington. 48:120-125.

FRITZ, J.S. e G.H. SCHENK, 1976. Quantitative Analytica Chem。 3a ed. Boston - London - Sidney - Toronto, Allyn and Bacon Inc. 689 P. 
GEERING, H॰R॰; E.E. CARY; L॰H॰P. JONES e W॰H॰ ALLAWAY, 1968 . Solubility and redox criteria for the possible forms of selenium in soils. Soil Sci. Soc. Am. Proc. Madison, Wiscon $\sin . \underline{32}: 35-40$.

GISSEL-NIELSEN, G., 1971. Selenium content of some fertilizers and their influence on uptake of selenium in plants. J॰Agr. Food Chem. Washington. 19:564-566.

GISSEL-NIELSEN, G., 1973. Uptake and distribution of added selenite and selenate by barley and red clover as influenced by sulphur. J. Sci. Food Agr. London. 24:649-655.

GISSEL-NIELSEN, G., 1975. Foliar application and pre-sowing treatment of cereals with selenite. z. Pflanzenern. Bodenk. 1:97-105.

GUTENMANN, W.H. e D.J. LISK, 1961. Determination of selenium in oats by oxygen flask combustion. J. Agr. Food Chem. Washington. 9: 488-489.

HAMDY, A.A. e G. GISSEL-NIELSEN, 1977. Fixation of selenium by clay minerals and iron oxides. Z. Pflangenernaehr Bodenkd. $140: 63-70$.

HOEDE, D.; R. MASSEE e H.A. DAS, 1975. The determination of selenium in dry organic material by thermal neutron activation and extration. Radiochem. Radional. Letters. Lausanne, Netherlands. 23:379-384.

HOFFMAN, I.; R.J. WESTERBY e M. HIDIROGLOU, 1968. Precise fluorometric microdetermination of selenium in agricultural materials. Journal of the AOAC, Washington. 51:1039-1042. 
HOLYNSKA, B. e K. LIPINSKA-KALITA, 1977. Optimization of wet digestion procedure of blood and tissue for selenium determination by means of ${ }^{75}$ se tracer. Radiochem. Radioanal. Letters. Lausanne, Netherlands. 30:241-245.

HOSTE, J., 1948. Diaminobenzidine as a reagent for vanadium and selenium, Anal. Chim. Acta. New York. 2:402-408.

HOSTE, J. e J. GILLIS, 1955. Spectrophotometric determination of traces of selenium with diaminobenzidine. Anal. Chim. Acta. New York. 12:158-161.

IHNAT, M. 1974a. Fluorometric determination of selenium in foods. Journal of the AOAC. Washington. 57:368-372.

IHNAT, M., 1974b. Collaborative study of a fluorometric method for determining selenium in foods. Journal of the AOAC.

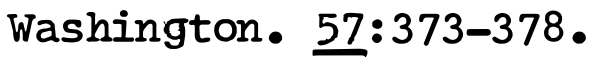

IHNAT, M., 1976. Atomic absorption spectrometric determination of selenium with carbon furnace atomization. Anal. Chim. Acta. New York. 82:293-309.

JOHNSON, C.A.; J•F. LEWIN e P.A. FLEMING, 1976. The determination of some "toxic" metals in human liver as a guide to normal levels in New Zealand. Anal. Chim. Acta. New York . 82: 79-82.

KELLEHER, W.J. e M.J. JOHNSON, 1961. Determination of traces of selenium in organic matter. Combined spectrophotometric and isotope dilution method. Anal. Chem. Washington. 33:14291432. 
KIRKBRIGHT, G॰F•; A.F. WARD e T॰S。WEST, 1973. Atomic emission spectrometry with an induction - coupled high-frequency plasma source. The determination of iodine, mercury, arse nic and selenium. Anal. Chim. Acta. New York. 64:353-362.

KRUG, F.J., 1975. Determinação de mercúrio por diluição isotópị ca subestequiométrica. Piracicaba, ESALQ/USP, 150 P. (Dissertação de Mestrado).

LEDERER, C.M.; J.M. HOLLANDER e I. PERLMAN, 1967. Table of Isotopes. 6a ed. New York, John Wiley. 210 p.

LEVANDER, O.A., 1967. Present knowledge of selenium. In:Present Knowledge in Nutrition. New York, Nutrition Foundation, 138$140 \mathrm{P}$.

LOTT, P.F.; P. CUKOR; G. MORIBER e J. SOLFA, 1963. 2,3-diaminonaphthalene as a reagent for the determination of milligram to submicrogram amounts of selenium. Anal. Chem., Washington 35:1159-1163.

MASSON, M॰R。, 1976. Determination of selenium and tellurium in organic compounds and organic materials-A review. Mikrochimica Acta. Wien, Austria. 4-5:419-439.

MAYNARD, L.A. e J.K. LOOSLI, 1966. Os elementos inorgânicos e seu metabolismo. In: Nutrição Animal. Rio de Janeiro, Pro grama de Publicações Didáticas - USAID. P.133-201.

MONTES, A.L., 1974. LOS Disolventes Orgânicos sus Propriedades, Aplicaciones y Análisis. Argentina, EUDEBA. 134 p.

NADKARNI, R.A. e B.C. HALDAR, 1971. Substoichiometric determina tion of selenium by neutron activation analysis. Radiochem. 
Radioanal。 Letters. Lausanne, Netherlands。 $\underline{7}: 305-311$.

NAKANARA, T.; M. MUNEMORI e S. MUSHA, 1970. Determination of selenium in sulfur by atomic absorption spectrophotometry. Anal. Chim. Acta. New York. 50:51-57.

OLsON, O.E., 1969. Fluorometric analysis of selenium in plants. Journal of the AOAC. Washington. 52:627-634.

OLSON, O.E., 1973. Simplified spectrophotometric analysis of plants for selenium. Journal of the AOAC. Washington. 56: 1073-1077.

OLSON, O.E.; I.S. PALMER E E.E. CARY, 1975. Modification of the official fluorometric method for selenium in plants. Journal. of the AOAC. Washington. 58:117-121.

PARKER, C.A. e L.G. HARVEY, 1962. Luminescence of some piazselenols. A new fluorimetric reagent for selenium. The Analyst, Picadiliy, London. 87:558-565.

RANN, C.S. e A.N. HAMBLY, 1965. The determination of selenium by atomic absorption spectrophotometry. Anal. Chim. Acta. New York. 32:346-354.

ROSENFELD, I. e O.A. BEATH, 1964. Chemistry of selenium. In : Selenium. New York and London, Academic Press, p. 299-332. SCHWARZ, K. e C.M. FOLTZ, 1957. Selenium as an integral part of factor 3 against dietary necrotic liver degeneration. J.. Amer. Chem. Soc. Easton, Pa-USA. 79:3292-3293.

TRELEASE, S.F., 1945. Selenium in soils, plants and animals. Soil Sci. Baltimore, Maryland. 60:125-131. 
UNDERWOOD, E.J., 1966. Trace elements in human and animal nutrition. 2a ed. New York and London, Academic Press, 429 p. WATKINSON, J.H., 1960. Fluorometric determination of traces of selenium. Anal. Chem. Washington. 32:981-983.

WATKINSON, J०H०, 1966. Fluorometric determination of selemium in biological material with 2,3-diaminonaphthalene. Analo, Chem。. Washington. 38:92-97.

WEAST, R.C., 1975. Handbook of Chemistry and Physics. 56 a ed., Cleveland, The Chemical Rubber Co. Press.

WILLARD, H.H॰; L.L. MERRITT, Jr. e J.A. DEAN., 1965. Fluorescence and Phosphorescence Methods. In: Instrumental Methods of Analysis. Princeton, New Jersey. D.Van Nostrand Company Inc. P. 370-395.

YOUNG, J.W. e G.D. CHRISTIAN, 1973. Gas-chromatographic determination of selenium. Anal. Chim. Acta. New York. 65: 127-138. 
8 - APENDICE 
PROCEDIMENTO DE ANALISE FLUORIMETRICA DE SELÊNIO:

1. Transferir $1 \mathrm{ml}$ de soro de sangue (ou $500 \mathrm{mg}$ de material ve getal seco e moido) para tubo de digestão.

2. Transferir $1 \mathrm{ml}$ de soluçã́o padrão de selênio na faixa de 0,05 a 1,00 ppm de selênio na ausência dás amostras para tú bo de digestão.

3. Adicionar $5 \mathrm{ml}$ de $\mathrm{HNO}_{3}$ concentrado e $2 \mathrm{ml}$ de $\mathrm{HCLO}_{4} 70 \%$ (para material vegetal, após adição de $\mathrm{HNO}_{3}$ e $\mathrm{HCLO}_{4}$, deixar a mistura em repouso por uma noite ou cerca de 12 horas) aos tubos de digestão.

4. Levar os tubos para o bloco digestor e decompor as àmostras inicialmente a 1600C e elevar a temperatura para 2100C e deixar até aparecerem os fumos brancos de $\mathrm{HCLO}_{4}$ e aquecer por mais 15 minutos.

5. Retirar os tubos do bloco digestor e deixar esfriar por 10 minutos.

6. Adicionar $2,5 \mathrm{ml}$ de HCl $(1+9)$ e colocar em banho-maria a. $900 \mathrm{C}$ por 30 minutos. Colocar funis na boca dos tubos para dar refluxo. Retirar do banho-maria e deixar esfriar.

7. Adicionar $5 \mathrm{ml}$ de EDTA $0,02 \mathrm{~N}, 1 \mathrm{ml}$ de cloridrato de hidroxa lamina $20 \%$ e agitar.

8. Adicionar $5 \mathrm{ml}$ de DAN $4 \times 10^{-3} \mathrm{M}$.

9. Adicionar 3 gotas de Azul de Tímol $1 \%$ (até cor rósea), neutralizar com NH 4 OH $6 \mathrm{~N}$ (até cor amarela) e deixar reagindo em banho-maria a 70ㄷ por 60 minutos.

10. Transferir a solução para funil de separação de $125 \mathrm{ml}$ e 
adicionar $5 \mathrm{ml}$ de ciclohexano.

1i. Proceder a extração agitando por 15 segundos.

12. Descartas a fase aquosa e analisar $4 \mathrm{ml}$ da fase orgânica por fluorimetria.

Para análise por fluorimetria fazer a leitura con tra o padrão 0,0 ppm de selênio, em fluorimetro com excitação a $366 \mathrm{~nm}$ e deteç̧ão da fluorescência a $525 \mathrm{~nm}$.

Os teores de selênio na amostra são calculados com base na curva padrão do selênio em solução aquosa (1tem 2). 